\title{
Refigurer le monde
}

La vieille femme salie : ses restes, ses narrations, sa résistance (Morvan $\mathrm{XX}^{\mathrm{e}}-\mathrm{XXI}^{\mathrm{e}}$ siècles)

Refiguring the world: A Soiled Old Woman and Her Leftovers, Narrations and Resistance (Morvan 20th-21st centuries)

\section{Caroline Darroux}

\section{OpenEdition}

\section{Journals}

Édition électronique

URL : https://journals.openedition.org/tc/8208

DOI : $10.4000 /$ tc. 8208

ISSN : 1952-420X

\section{Éditeur}

Éditions de l'EHESS

Édition imprimée

Date de publication : 31 octobre 2016

Pagination : 470-493

ISBN : 9782713225291

ISSN : 0248-6016

\section{Référence électronique}

Caroline Darroux, «Refigurer le monde », Techniques \& Culture [En ligne], 65-66 | 2016, mis en ligne le 31 octobre 2018, consulté le 29 septembre 2022. URL : http://journals.openedition.org/tc/8208 ; DOI : https://doi.org/10.4000/tc.8208 


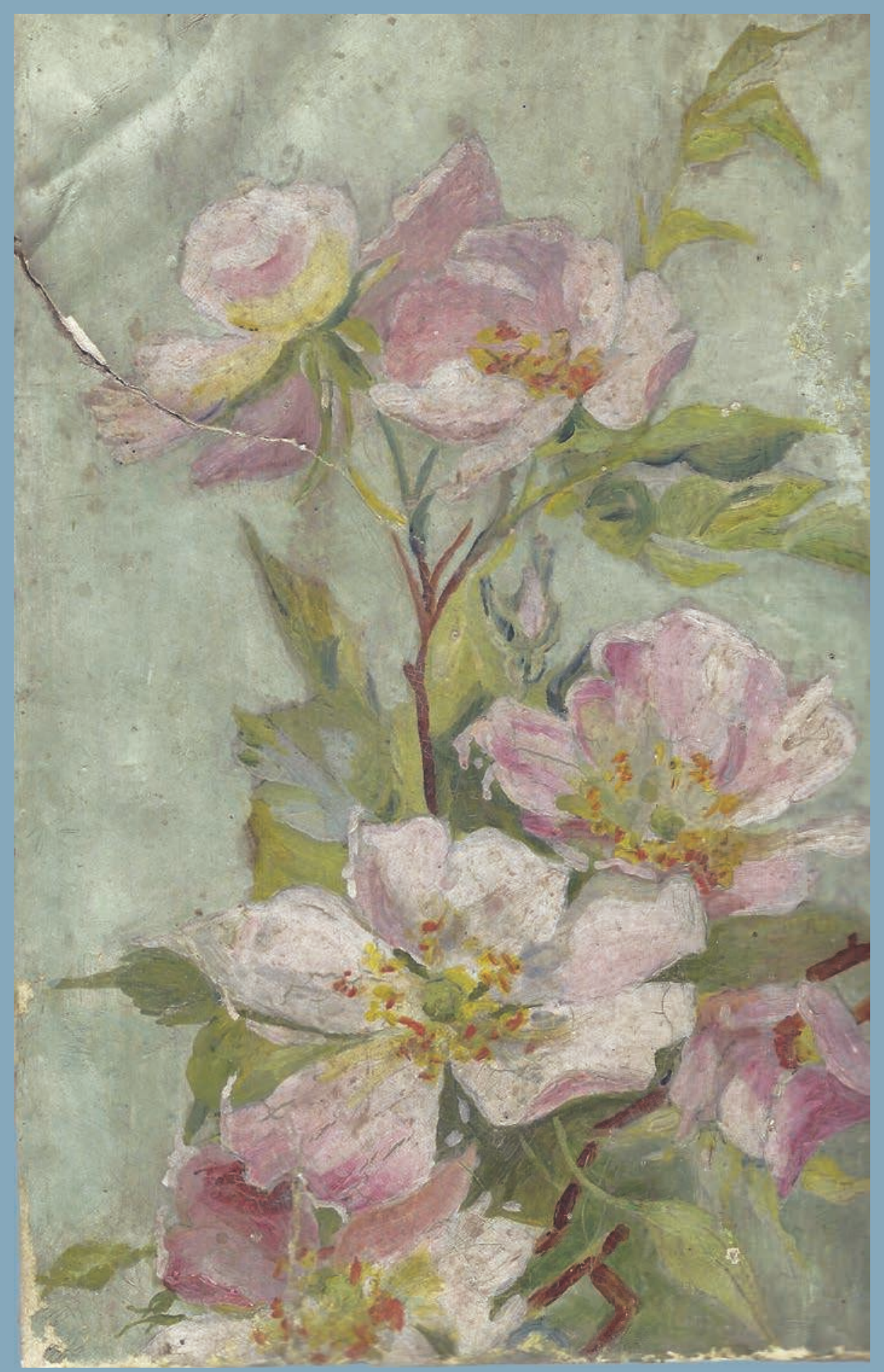




\title{
Refigurer le monde
}

\section{La vieille femme salie: ses restes, ses narrations, sa résistance (Morvan $\mathrm{XX}^{\mathrm{e}}-\mathrm{XXI}^{\mathrm{e}}$ siècles)}

\begin{abstract}
«Il n’y a pas une interprétation "correcte" de cette succession d'images. Elle tente de suivre les réflexions d'une vieille femme sur sa vie. Si on lui demandait soudainement: "À quoi pensez-vous?", elle inventerait une réponse simple, parce que si l'on prend cette question au sérieux, il devient impossible d'y répondre ${ }^{1}$.»
\end{abstract}

Comment démêler la matière du récit de la matière? Restes de catastrophe, restes du corps, souvenirs du vécu, assemblement hétéroclite produit par la violence d'une irruption ou le travail du temps, chaque expérience du désordre des restes, aussi infime soit-elle, ouvre une brèche dans l'ordre du discours et dans «le monde», tel qu'il est ordonné par la société occidentale moderne. Une forme verbale (Jolles 1930) particulière advient, pour parler de l'immonde: manière de recyclage où prend sens le divers (Segalen 1978, Glissant 1996). La thématique de ce numéro de la revue Techniques ECulture pose des difficultés à la fois d'ordre méthodologique mais également épistémologique dans la mesure où elle s'attache à la mise en discours (scientifique) des restes. Cette contribution souhaite aborder ce que peuvent générer, dans l'ensemble des discours, les restes et leur matérialité: amas d'éléments qu'on ne veut pas/qu'on ne peut pas détruire. Ces problématiques se retrouvent dans des «éclats narratifs» que je tente de rassembler dans mon travail de recherche sur une figure féminine, sujet de conversations aux contours ambigus, être liminaire qui est aussi incarné par des personnes réelles (Darroux 2011). Sur le terrain, un type de récits a en effet particulièrement fait sens par son extrême rareté ou plutôt par les conditions très particulières qui permettaient qu'ils soient dits: les récits qui racontent certaines vieilles femmes. Une dialectique s'y opère entre la notion de reste et un récit de résistance à l'exclusion. Les restes y tiennent une fonction: le contact avec les restes est le lieu d'un renversement sémantique capable d'engendrer un phénomène de sidération où se déclenche une dynamique. En l'occurrence: le récit ne fonctionne que si l'on fait l'expérience sensible des restes. Afin d'explorer la rupture discursive que cette dynamique engendre, j’ai souhaité sortir des conventions du discours scientifique pour envisager une forme verbale diffractée: image, description, transcription, récit ethnographique et refiguration ${ }^{2}$ scientifique, mis en résonance à la manière d'un kaléidoscope ${ }^{3}$. 


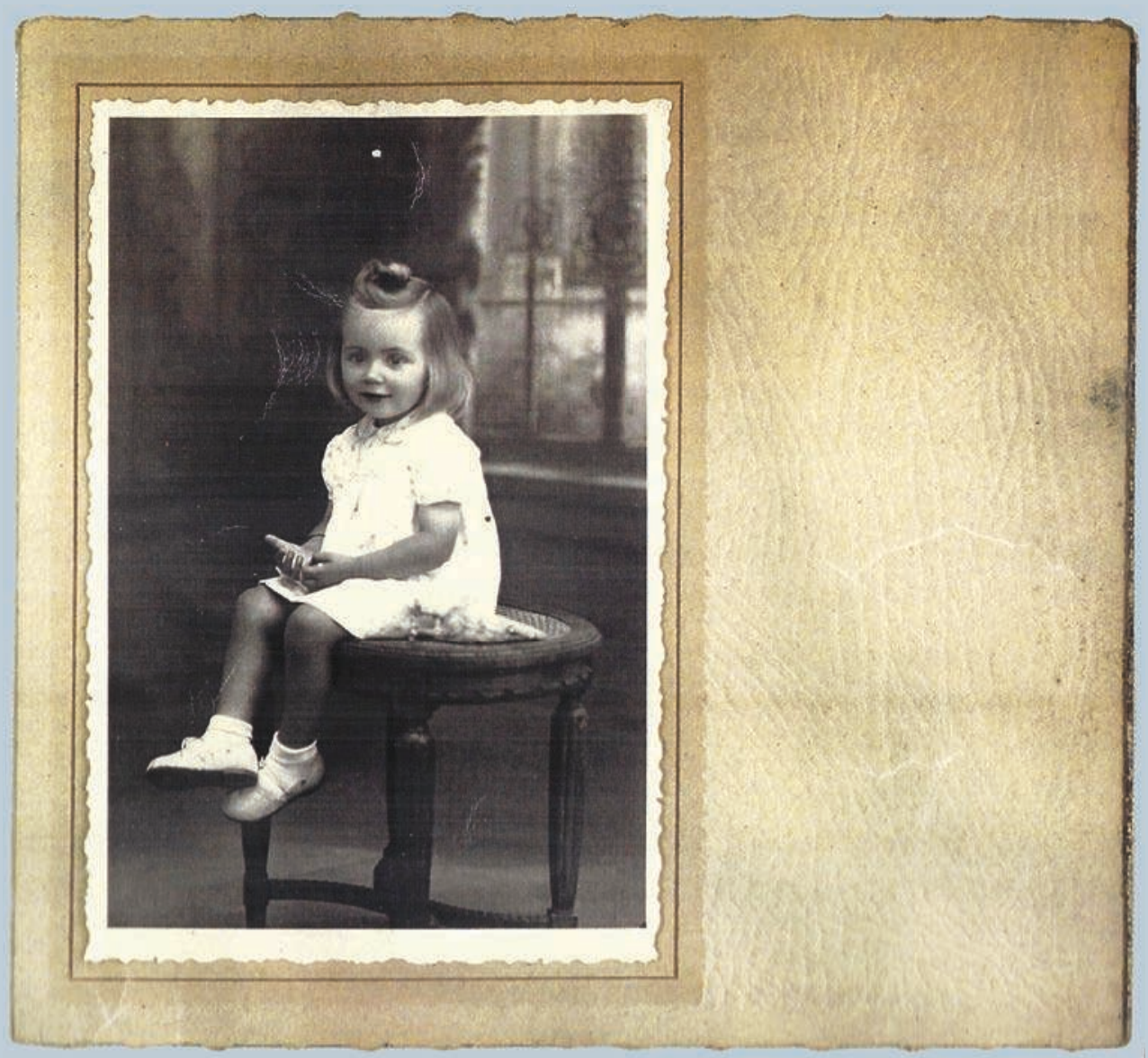

1, 2, 3. Triptyque de photographies d'Henriette: enfant assise (environ 1930), jeune fille «en pied» en habit de communiante (environ 1940) et vieille femme «en pied» devant une porte ouverte (environ 2000). Les deux premières photographies ont été prises dans un studio, la dernière sur le perron de sa maison. Ce triptyque a été réalisé par une habitante du village (Marinette) à partir de photos retrouvées à différents endroits dans la maison d'Henriette, elle a reproduit le triptyque en plusieurs exemplaires et l'a offert à une dizaine de personnes entre 2003 et 2006: famille, amis, connaissances et moi-même. 

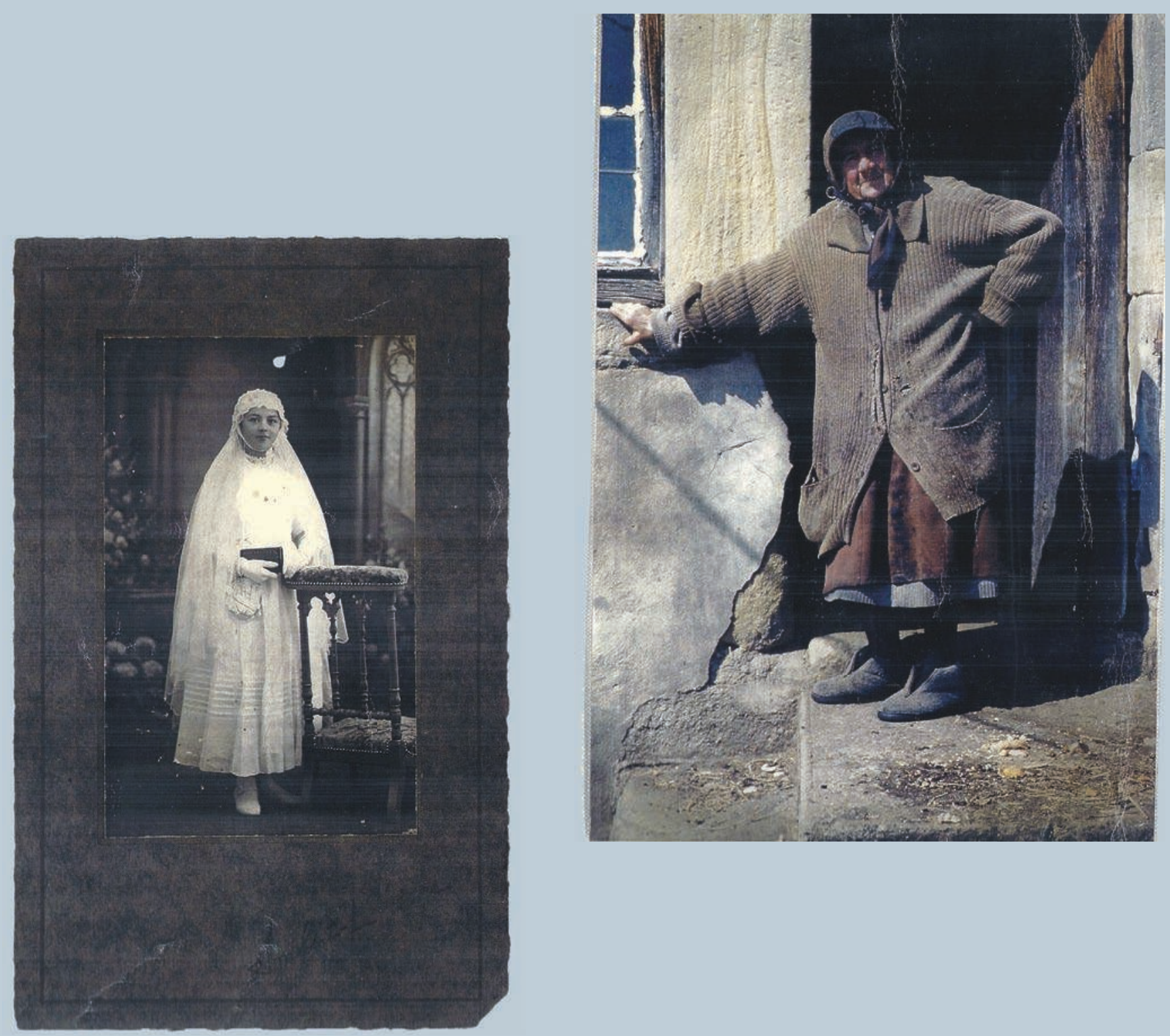


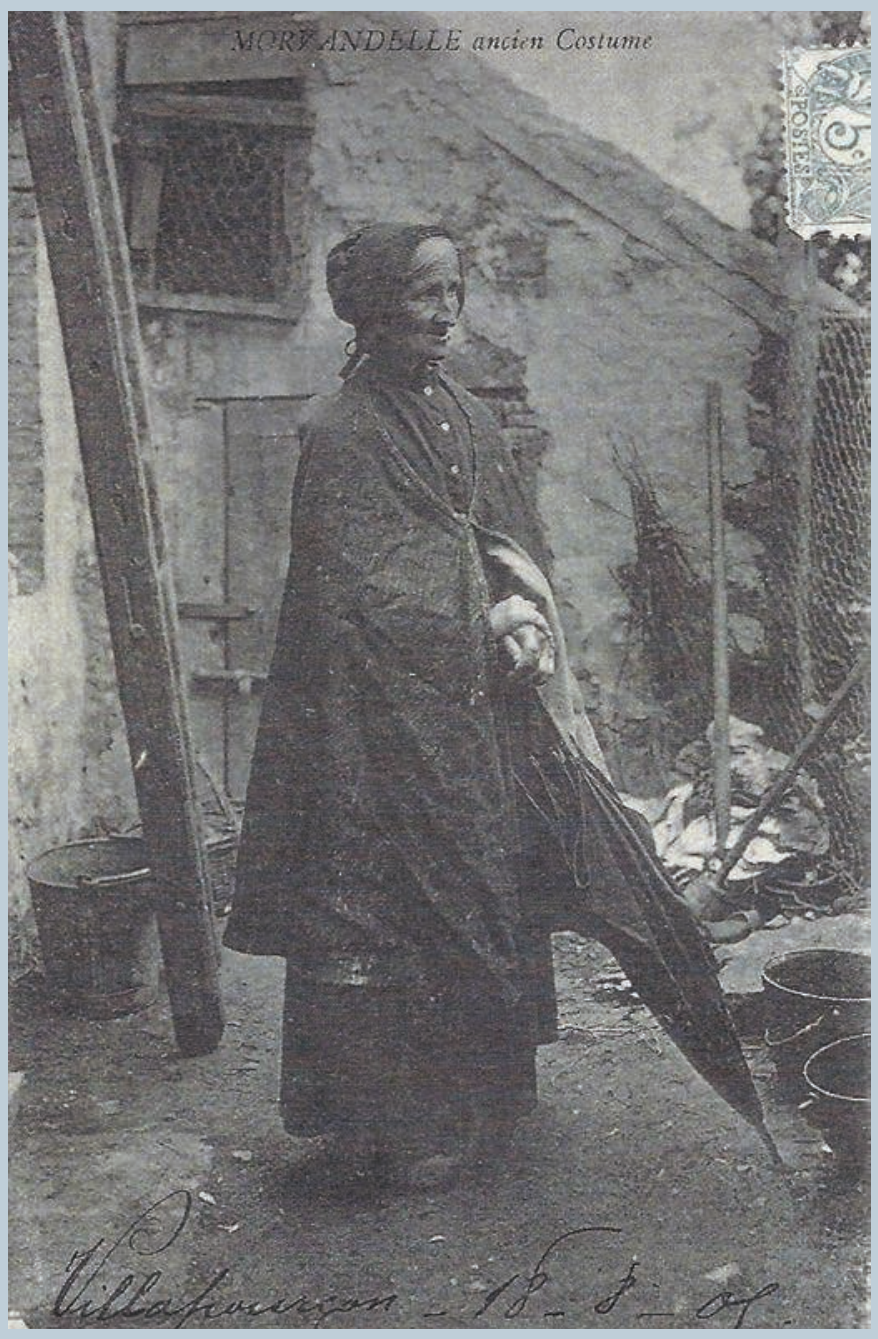

4. Carte postale qui reproduit une photographie de vieille femme «en pied». Elle pose, en extérieur, vêtue d'une cape sombre et tenant un parapluie, elle porte une coiffe sombre, on distingue ses sabots. En arrière-plan, une accumulation d'emballages usagers et rassemblés en tas, un ballet, des seaux. Un titre est placé en haut de la carte postale: «Morvandelle. Ancien costume». Une inscription en bas: «Villapourçon, 18/08/09». La carte postale a été éditée à Chalon-sur-Saône.

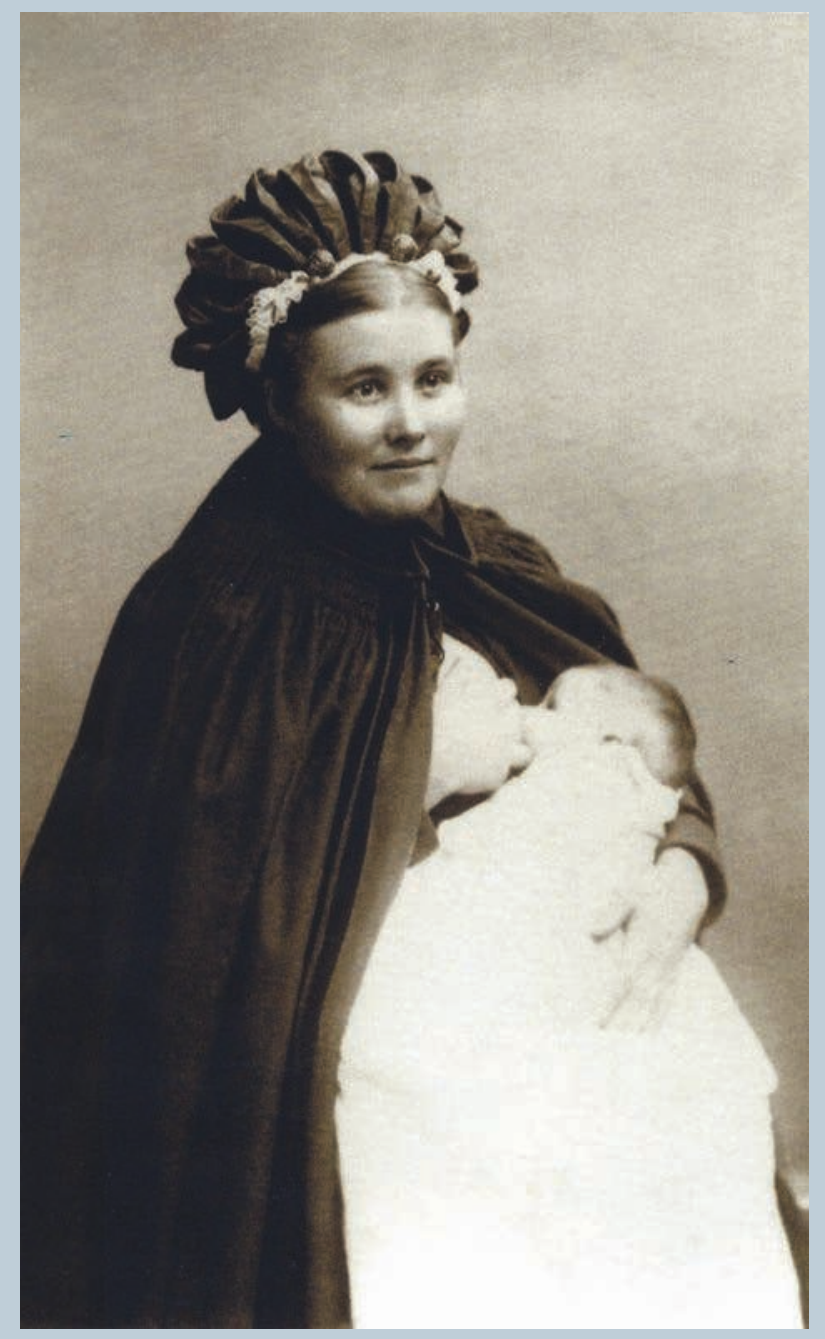

5. Photographie d'une jeune femme qui pose en donnant le sein à un enfant. C'est une photographie de studio. La jeune femme est vêtue d'une cape sombre sur un habit blanc qui produit un fort contraste. Elle porte la riche coiffe des «Nourrices du Morvan» avec rubans précieux et épingles. Cette photo n'est pas datée mais a vraisemblablement été prise entre 1890 et 1910. Portrait d'ouverture de l'ouvrage Le Morvan et ses nourrices (Doreau \& Renault 2004), dont voici la légende: «Louise Cailloux allaitant son nourrisson, photographie C. Lagriffe, 203 rue Saint-Honoré, Paris.» 


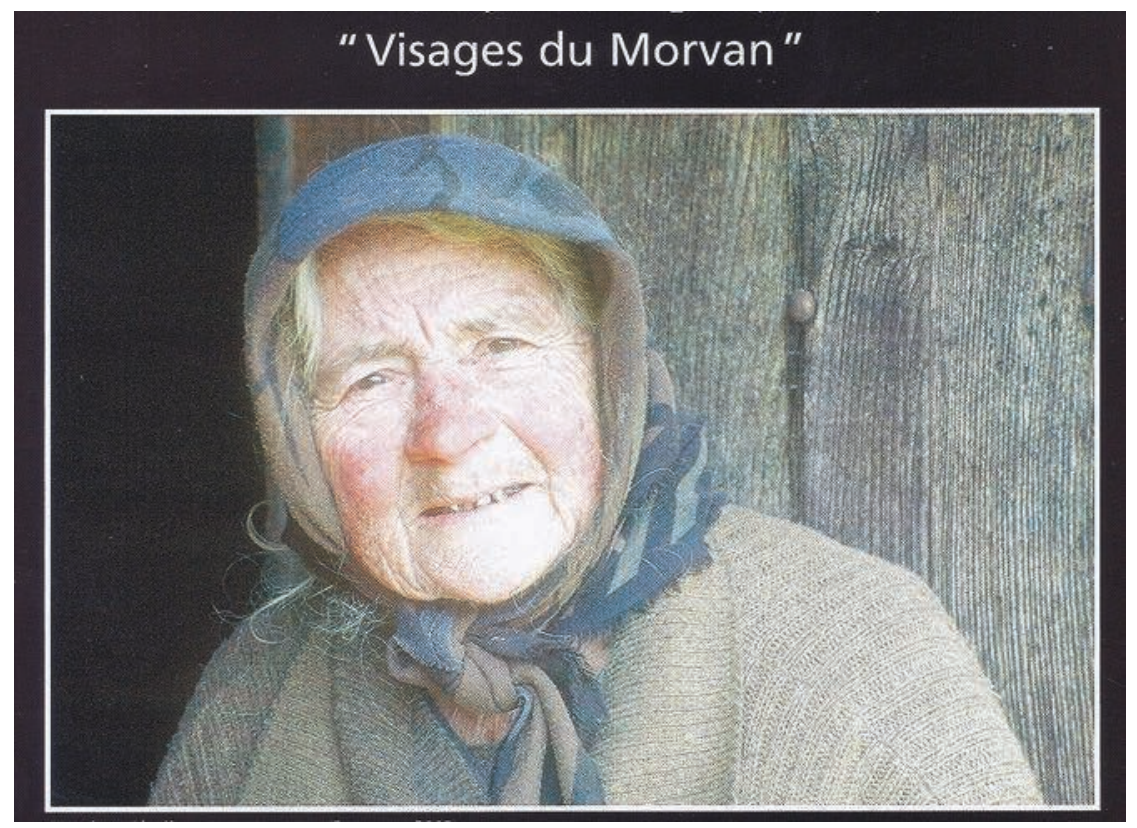

6. Portrait élargi du visage d'Henriette, presque «en buste». Il s'inscrit dans une collection intitulée «Visages du Morvan». Une légende sous la photographie permet d'identifier son nom et son prénom, ainsi que le village. La mise en scène est minimale, la personne pose devant une porte ouverte et sourit. Quatrième de couverture (vernis brillant) d'un magazine trimestriel qui traite essentiellement de thématiques patrimoniales (nature, culture, histoire): Vents du Morvan. Ce magazine est essentiellement diffusé dans les communes du centre de la Bourgogne faisant partie ou limitrophes du Parc naturel régional du Morvan, revue n॰6 (2002).

\section{Transcription d'enquête}

Dans des circonstances de complicité particulières, voici le récit qui me fut raconté par Marinette:

«J'y suis allée dimanche moi! Ce n'est pas plus propre! Même de plus en plus sale! [Mon mari] Touène, l'autre jour, lui a débloqué sa porte, parce qu'elle met tellement de saletés derrière qu'il ne pouvait plus ouvrir la porte. Alors il a poussé un bon coup la porte. [Henriette] dit [Marinette prend une voix rauque et en colère] : "Câsses mouais donc mai pourte!" (Casse-moi donc ma porte!) [Rire] Oh il a pensé: "Ce n'est pas bien difficile" parce que les chats peuvent passer dessous! [sourire] C'est tout emmanché. Il dit: "Ma foi, il faut bien qu’on l'ouvre ta porte!" Parce qu'à force de mettre des saletés, elle n'a même pas le courage de les empiler!»

« [...] Une fois [...] quand je suis revenue de chez elle, je me suis changée et je me suis lavée! Je ne suis pourtant pas délicate! Parce que j'étais restée au moins deux heures, on avait bien parlé, sur une chaise... on ne voit plus que c'est du bois! Il y a les pattes des chats qui ont emmené de la terre.»

«Tu devrais aller la voir. Moi je peux t'y mener un jour si tu veux. » 


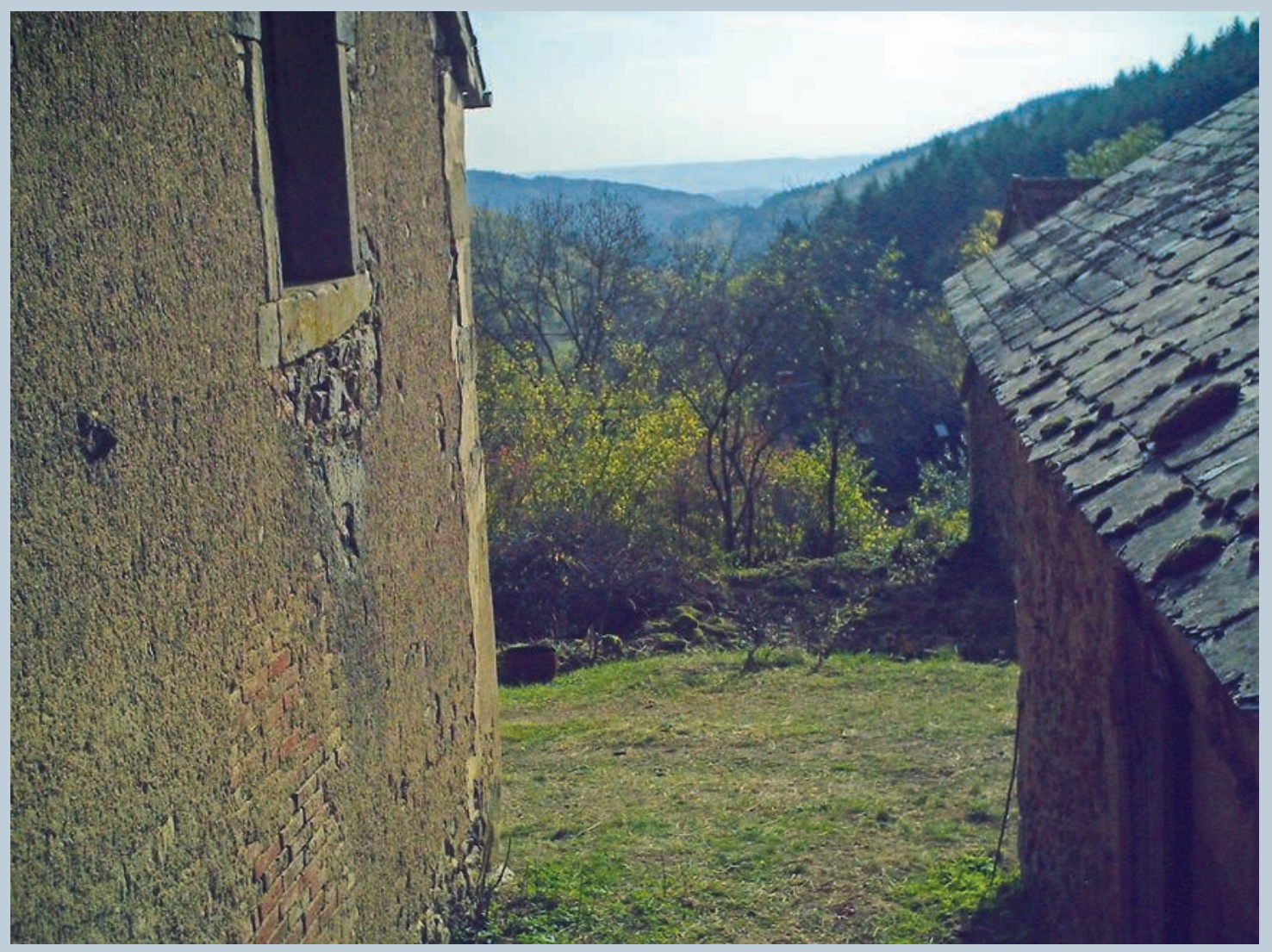

7. Vue depuis la maison d'Henriette. À droite, on aperçoit le toit du poulailler en usage jusqu'à la mort d'Henriette. Les œufs, les châtaignes et les pommes de terre qu'elle achetait à son voisin étaient l'essentiel du régime alimentaire d'Henriette. 

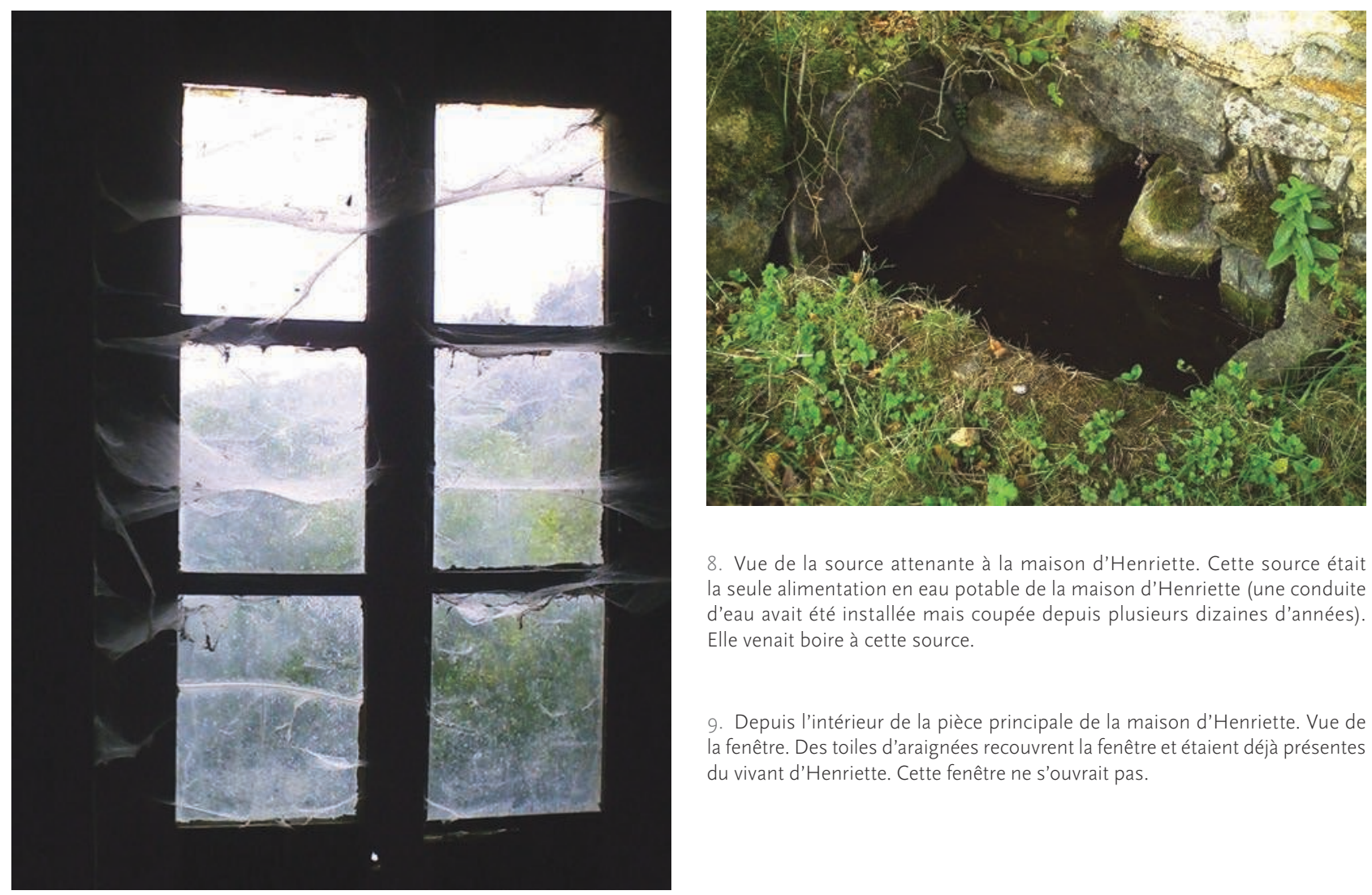

8. Vue de la source attenante à la maison d'Henriette. Cette source était la seule alimentation en eau potable de la maison d'Henriette (une conduite d'eau avait été installée mais coupée depuis plusieurs dizaines d'années). Elle venait boire à cette source.

9. Depuis l'intérieur de la pièce principale de la maison d'Henriette. Vue de la fenêtre. Des toiles d'araignées recouvrent la fenêtre et étaient déjà présentes du vivant d'Henriette. Cette fenêtre ne s'ouvrait pas.

\section{Récit ethnographique}

J'y suis retournée ce matin, à la maraude. Deux heures de marche pour la rejoindre par les bois, pour qu'on ne me voie pas. À l'intuition, sans carte ni boussole, j'ai retrouvé le chemin le plus sûr. Grâce aussi aux railleries de ce geai qui semblait m'indiquer le chemin à chaque nouvelle intersection. La maison était là, elle m'est apparue, avec ses couleurs de vieille carte postale, son silence de fantôme. Vision d'archaïsme. J'ai pris le temps d'observer. Chaque chose, les rayons dorés du soleil qui inondent les détritus: «Elle jetait dedans». C'est vrai que les alentours des bâtiments restent propres. Dans l'une des pièces, sur un tas d'ordures, un bol majestueux, cassé, souvenir d'une ancienne richesse, le couvercle d'une soupière en porcelaine, des ballerines blanches et immaculées jetées dans la cave. Sensation étrange d'être hors du temps. 
10. Photographie de la pièce principale d'habitation d'Henriette prise depuis le pas de la porte fermée, en 2003 . On recon naît une cuisinière à bois, une pile de bois, une armoire ouverte, des vêtements posés sur une chaise, un amoncellement de déchets par terre qui étaient déjà mentionnés du vivant d'Henriette comme un risque d'incendie. Les murs et le plafond sont noirs du fait de la fumée qui s'échappait de la cuisinière d'Henriette (elle laissait le couvercle ouvert pour permettre un meilleur tirage). La cuisinière et l'intérieur des portes du placard, ainsi qu'un vêtement font contraste par leur couleur blanche. L'amoncellement de vêtements immaculés témoigne des sacs de vêtements usagers que des visiteurs bien intentionnés venaient offrir à Henriette pensant qu'elle n'avait pas de quo se vêtir. On devine un dessus de cheminée à motif jaune et rouge bien ordonnancé. On distingue de la fumée.

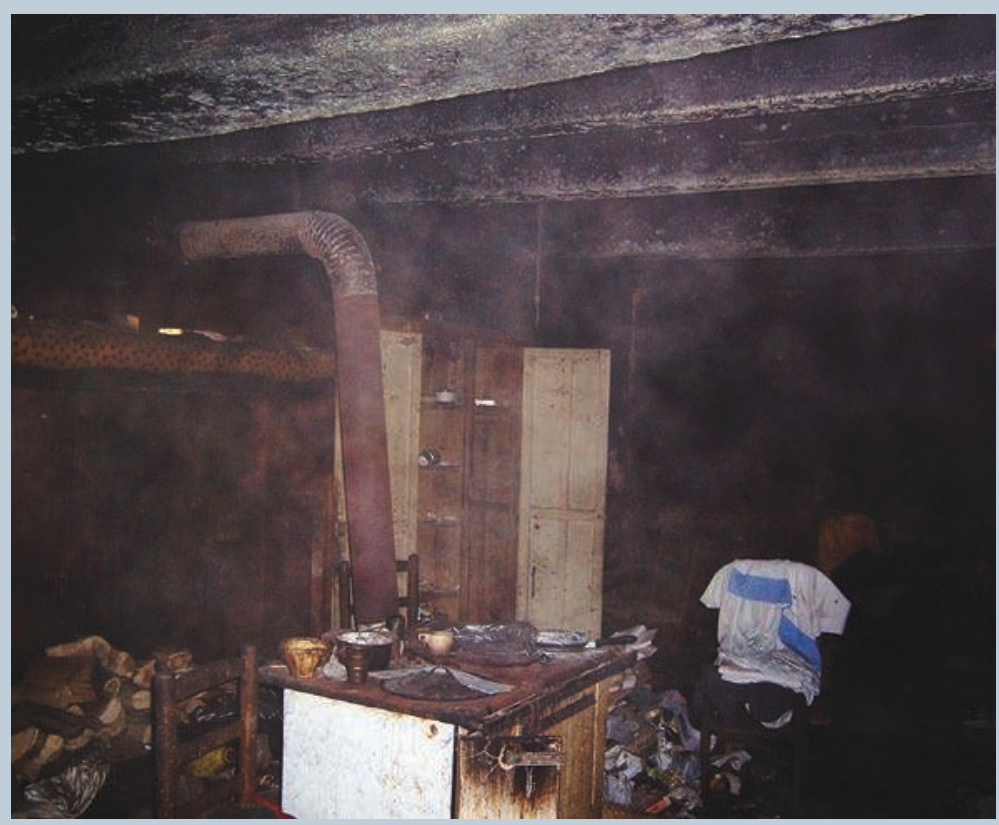

11. Reproduction de l'estampe de Jacob de Gheyn II, A Witch's kitchen en 1600 . Elle représente un intérieur, un antre de sorcières. Trois sorcières sont en train de préparer un bouillon à partir d'un cadavre et d'éléments hétéroclites: onguents, élé ments animaux, etc. L'une d'entre elles est accroupie et lit dans un livre à gauche. De la fumée noire s'échappe de l'antre. La lumière provient d'un feu qu'on ne distingue pas à gauche et agrandit l'ombre portée de l'une des sorcières de droite sur le mur opposé. La troisième sorcière est assise sur un tabouret. Un ballet se distingue au sol au premier plan. Une sorte de garde-manger est suspendu au centre de la scène. Des chats et souris mangent ce qui jonche le sol.

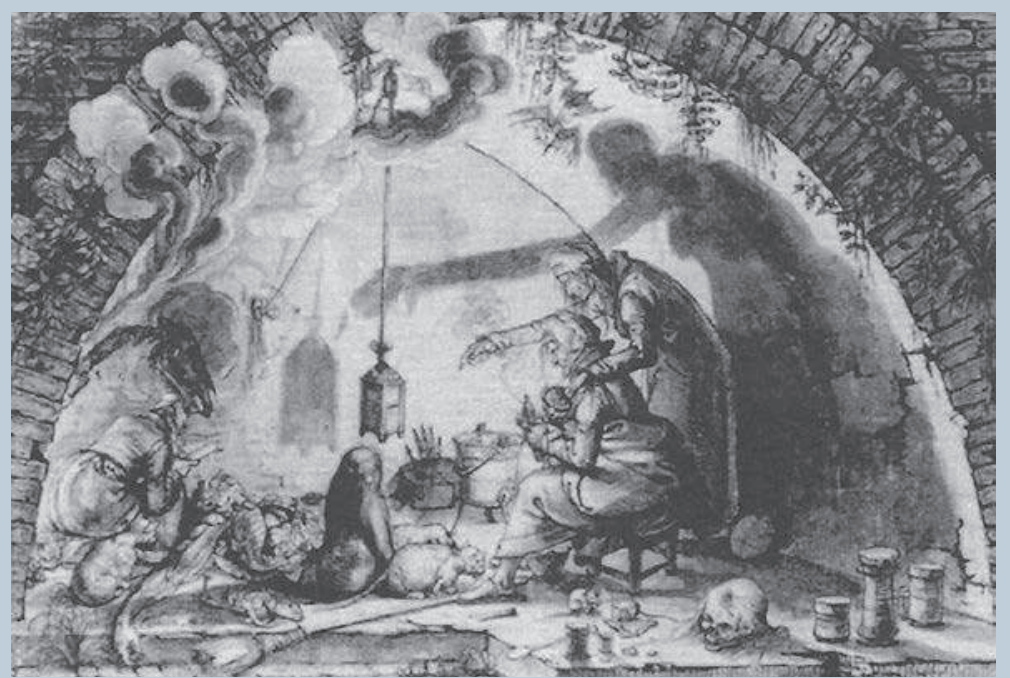



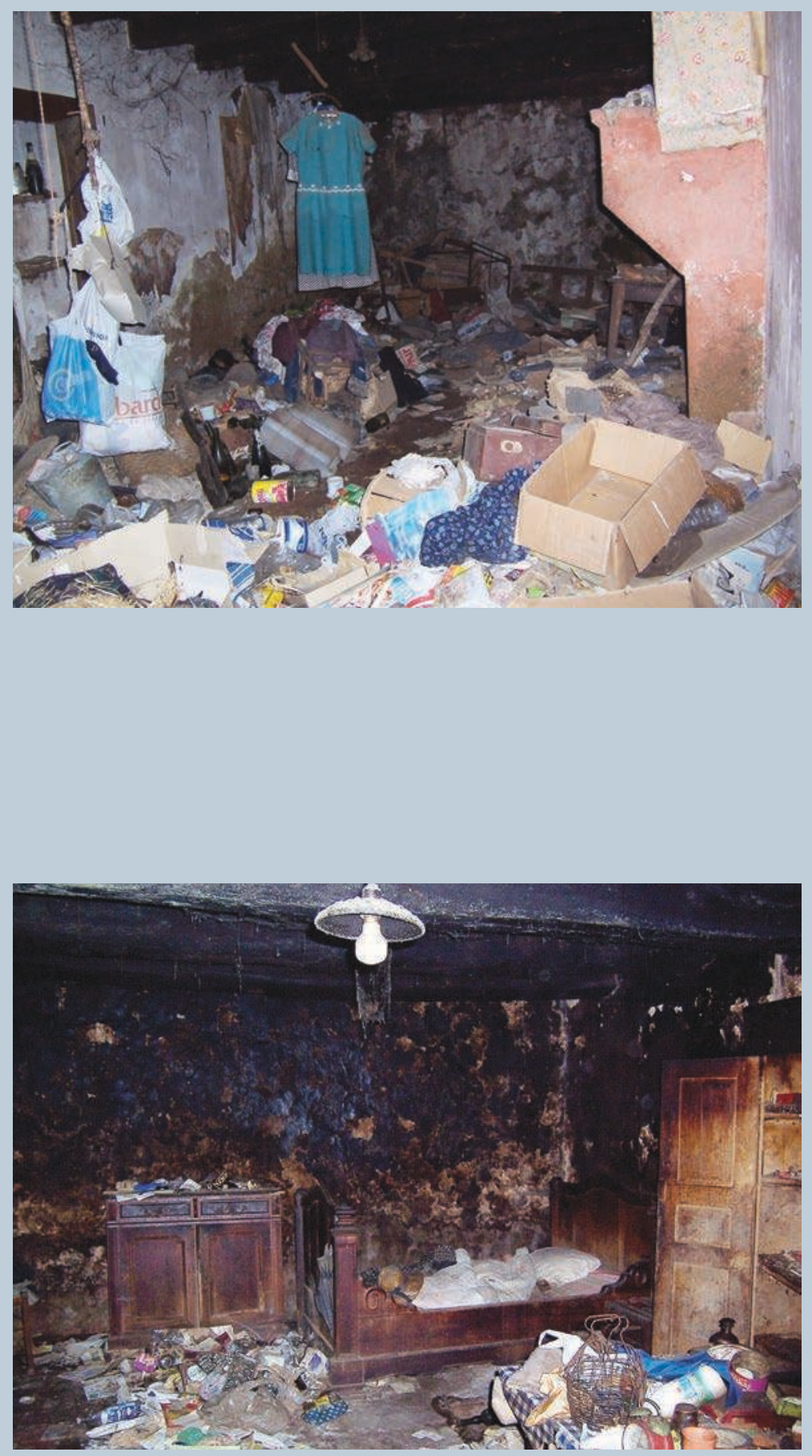

12. Photographie de l'intérieur d'une pièce d'habitation de la maison d'Henriette, prise en 2003 depuis le pas de la porte ouverte. On y distingue des emballages usagers. Dans cette pièce, les emballages étaient davantage classés que dans l'autre, rassemblés par «famille». On voit des vêtements de femme, des livres en état de décomposition. Parmi ces livres, nombre de journaux (dont certains remontaient à 1970) et de documents administratifs mélangés aux actes de propriété, aux talons de chéquiers. Des chaises renversées et trop décomposées pour être réutilisées. Des bouteilles pleines: ses réserves. Les murs sont abîmés par l'humidité, les pièces de la maison sont très humides car les murs du fond sont complètement enterrés (cela semble s'être opéré avec le temps, les intempéries et la forte pente) et l'eau ruisselle. Le plafond est noir.

13. Photographie de l'intérieur de la pièce principale d'habitation de la maison d'Henriette prise en 2003 depuis le pas de la porte fermée. On distingue des emballages vides, beaucoup de personnes témoignent de sa tendance à conserver les emballages, notamment de lait, ils sont rassemblés dans le même coin. Elle jetait par terre ses emballages. On distingue également de la vaisselle, dont des porcelaines de Limoges (identifiées après nettoyage), la famille d'Henriette était réputée «la plus riche du hameau», il se raconte qu'elle avait un seau à champagne en or. Quelques meubles semblent avoir été ouverts et vidés. Son lit est situé dans le coin au fond de la pièce, c'est à côté de ce lit qu'on a retrouvé son corps le jour de sa mort, une tache de sang s'était répandue sur toute l'épaisseur du matelas. On aperçoit une lampe suspendue électrique, la seule lumière de la maison. L'abat-jour est en verre et d'une facture très recherchée (identifiée après nettoyage). Henriette appelait l'électricité «la fée électrique». Les murs et le plafond sont noirs, et attestés semblables depuis des dizaines d'années. Les draps du lit et quelques emballages font contraste par leur couleur blanche. 


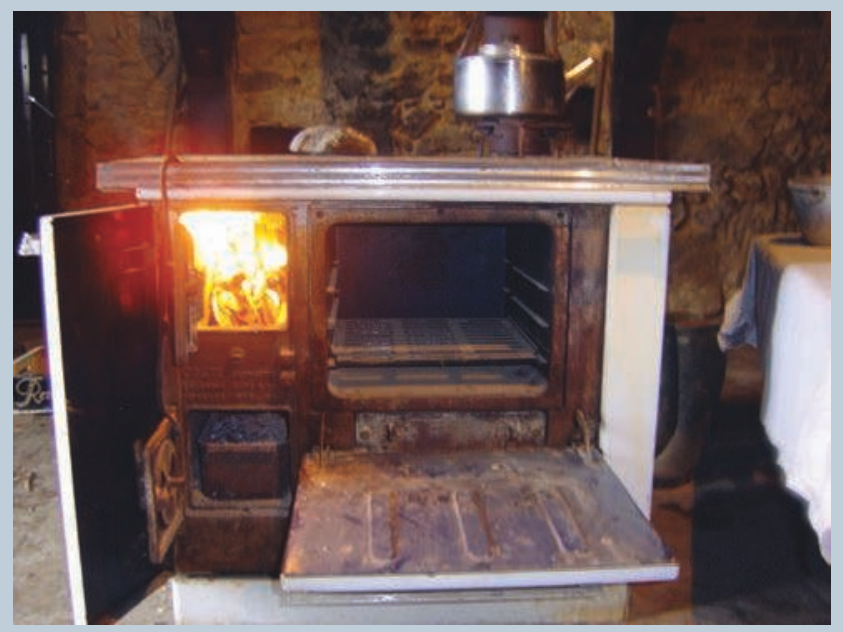

15 et 16. Explorer la maison d'Henriette.
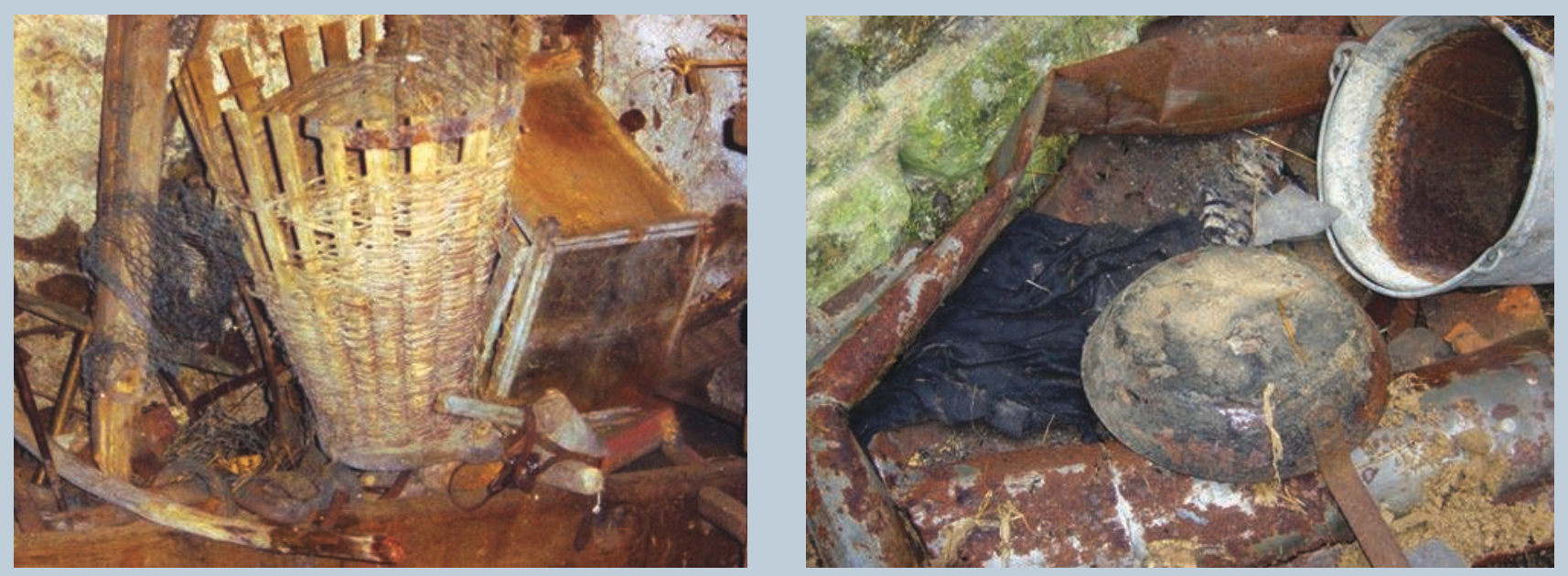
Intimité du chaos avec le beau, ces tasses de porcelaine de Limoges en parfait état de conservation, au milieu des immondices. Quels enseignements ensuite? Ce que tu mas montré, toi la femme sale du passé, c'est l'ordure de notre société qui t’a ensevelie. Les formes suspectes de ces déchets, le dégoût, l'écœurement à vomir de cette odeur remuée, de ces années de rejets: papiers maculés, plastiques gras, boîtes de conserve ouvertes, bois pourri, nourriture avariée. Entrailles oubliées de quelques décharges publiques, j’ai senti entrer dans mes poumons cette vapeur nauséabonde, elles ont taché mes mains, mon visage, mes yeux ont débordé, comme mes rêves. Rêves que je dors dans les détritus, que je me couvre de ces ordures, qu'il n'existe plus rien d'autre.

Un matin, que je triais depuis quelques heures les papiers gras et les briques de lait vides, les boîtes de sardines périmées et les journaux en lambeaux, j’ai trouvé ce petit tableau un peu noirci par la saleté. Est-ce la fatigue, le désespoir, l'affection qui s'immisçait dans la reconstitution appliquée de toute cette vie par l'archéologie de ses restes, je fus prise d'une vive émotion. Je regardai ce trait fin, ces petites roses sauvages fragiles et bien connues, panacée contre les affections hivernales et les problèmes d'estomac. Je reconnus l'écriture impeccable d'Henriette, que je connaissais avec expertise après avoir «épluché» chaque document administratif et quotidien devenu carreau temporaire-permanent à la place d'un morceau de verre brisé, ou fourré dans quelque endroit improbable. Puis cette cicatrice qui tailladait le fragile pétale, la saleté qui recouvrait le tout. Je crus la voir elle. Et me revint alors en mémoire ce petit conte étiologique retrouvé sur d’autres manuscrits épluchés aux Archives départementales de la Nièvre, dans le corpus collecté par Achille Millien. Un homme, qui habitait le village de Murlin lui raconta en 1899:

«Avant, la huppe se faisait un très beau nid, dont les parois étaient garnies d'écus d'or. Mais les hommes, toujours avides, se mettaient à la recherche de ces nids et les détruisaient pour prendre l'or. Alors la huppe remplaça l'or par de l'or-dur: depuis elle niche en paix. ${ }^{4}$

Un des anciens du village me disait l'autre jour, à propos de quelqu'un qui n'est pas bien propre, « on dit qu'il est sale comme une huppe».
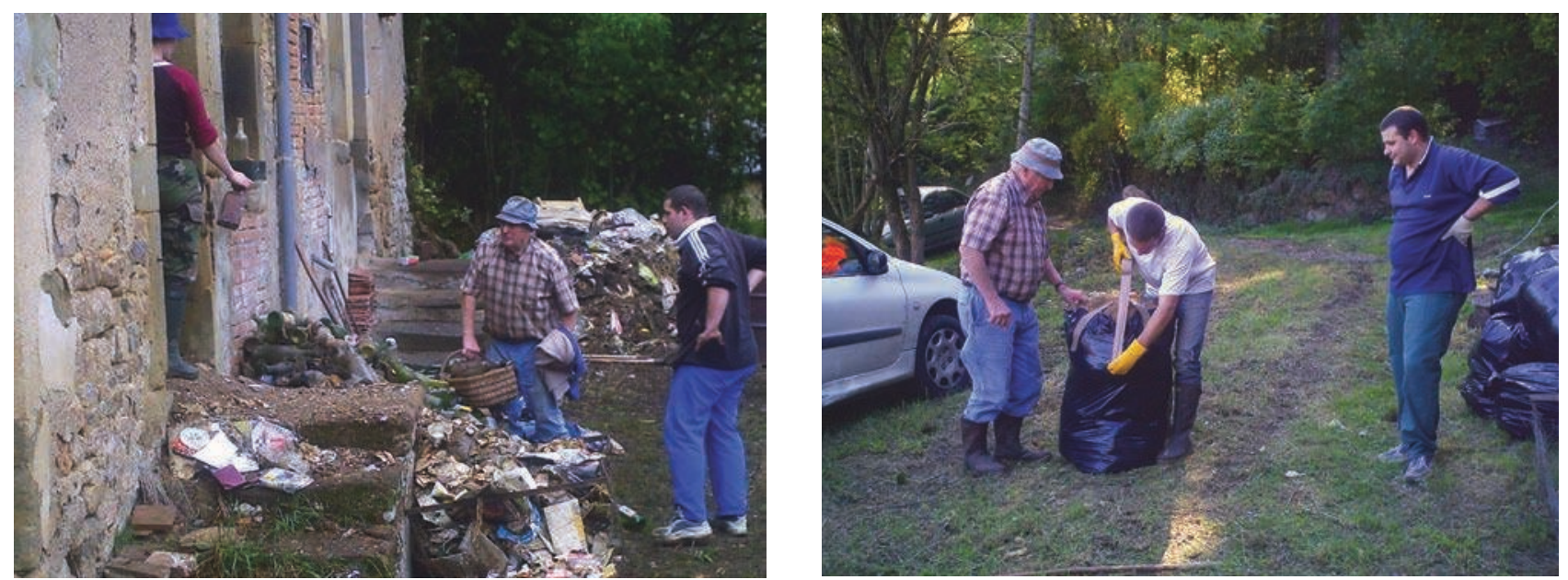

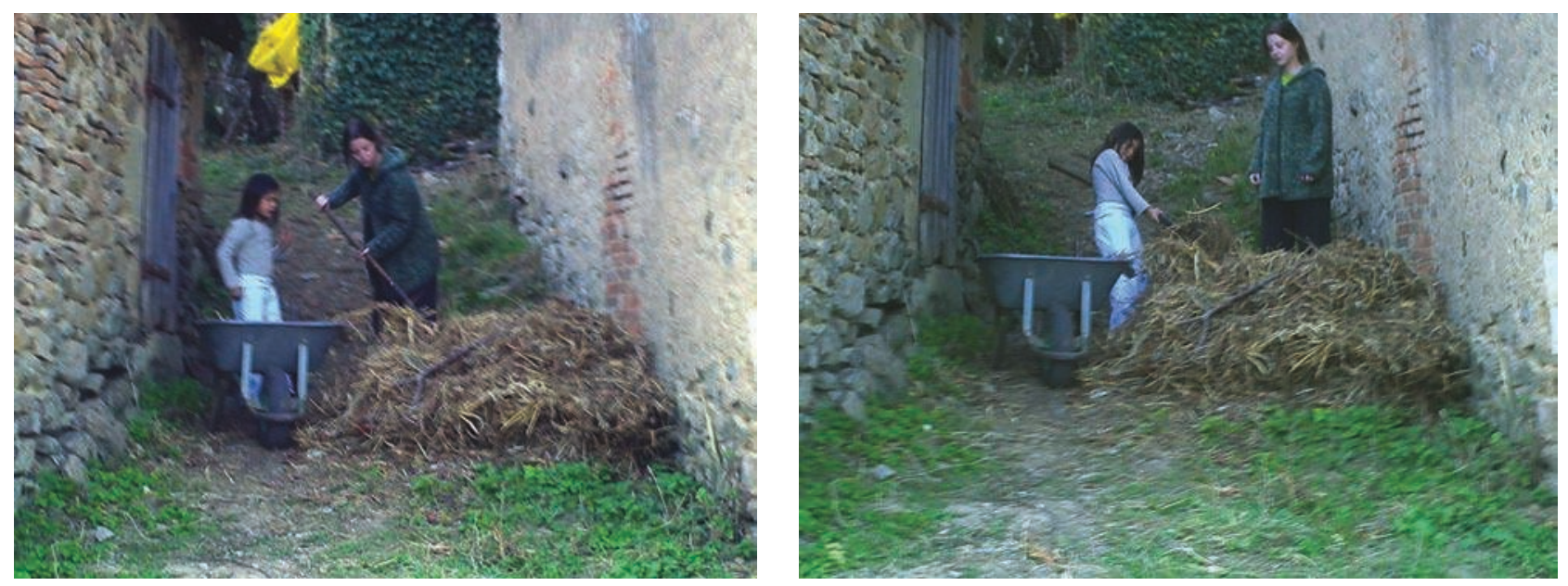

\section{Refiguration}

Le Morvan, comme tout lieu habité, est travaillé par un feuilletage narratif complexe. Mon propos s'inscrit dans l'étude de l'économie générale du récit territorial: comment, au fil du temps, un récit collectif endogène (impacté par les récits exogènes) va singulariser un territoire? Dans ce cadre, les notions de «restes» et de «saleté » interagissent avec le récit collectif qui configure ce territoire. Ma démarche d'« ethnographie du récit» a pour objectif non pas:

«de savoir en quoi le récit est déterminé [...], mais en quoi il est déterminant, c'est-à-dire qu'il conforme, dans l'instant de sa profération, le passé et le devenir et que, d’une certaine façon, il le crée» (Pelen 2004).

Elle pose la question «du rapport dynamique entre l'identité narrative de l'individu et celle de la collectivité à laquelle celui-ci appartient» (Pelen 2008). Les récits n’y sont pas appréhendés selon des catégories imperméables (anecdote, conte, etc.) mais comme participant d'un même continuum narratif. L'économie générale du récit collectif constitue une stratification, à l'intérieur de laquelle les récits peuvent être reliés par des «chevilles» narratives, à la manière d'un ouvrage de charpente (dans la diachronie et la synchronie) $)^{5}$. Le Morvan se situe au centre de la Bourgogne ${ }^{6}$, territoire de moyenne montagne, dont l'existence administrative est officialisée en 1970 par la création du Parc naturel régional, mais dont l'existence dans les représentations est bien antérieure (sans que la datation soit évidente). Comme beaucoup de régions rurales montagneuses, il a été qualifié dans les écrits du xix et du début du Xxe siècle (par Vidal de LaBlache ${ }^{7}$ et Gaston Roupnel ${ }^{8}$ notamment) comme un territoire «en retard», «arriéré», «étrange». Ce lexique a persisté jusqu'à une époque très récente. Ces attributs, ayant bénéficié d'une diffusion écrite localement et dans la région parisienne, ont longtemps impacté le récit collectif territorial. On y retrouve, comme dans beaucoup d'autres territoires similaires, cet adage devenu définitoire:

«Du Morvan il ne vient ni bon vent ni bonnes gens». 
Au démarrage de cette enquête narrative dans un village morvandiau, j’ai repéré une forme très particulière de récits dans les conversations, lorsqu'on me parlait de cette vieille femme: Henriette. À chaque fois, les paroles restaient évasives ou se disaient à mots couverts pour que je n'entende pas. Ces récits, du fait de leur rareté et de leurs conditions spécifiques d'arrivée dans la conversation, ont mobilisé mon attention, jusqu'à devenir un objet de recherche. Le récit de Marinette fut le premier qu'il m’ait été donné d'entendre au sujet d'Henriette ( 3 ans après le démarrage de l'enquête). Je fus un peu médusée par le caractère très évocateur de sa narration. Pour le coup, les détails étaient exprimés pardes termes peu fréquents dans les conversations politiquement correctes: les «saletés» et la saleté de cette personne. Ces propos tranchaient avec l'empathie qu'elle témoignait en me donnant le triptyque de photographies d'Henriette: «Pauvre Henriette, ça montre la déchéance... ». Les témoins de l'enquête m'ont très vite fait comprendre que, pour en savoir plus, je devais «aller la voir» et écouter son histoire racontée par elle-même avant de pouvoir accéder aux récits qu'en font les autres. Ce que je fis. Elle était en parfaite cohérence avec le discours collectif et ambivalent qui circulait à son propos, tel qu'il était arrivé à ce moment jusqu'à moi : force inhabituelle de signifiants symboliques et concrets qui l'entouraient (imitation du cri de chouette pour la faire sortir, une vingtaine de chats noirs devant ses pieds lorsqu'elle me parle, un visage souriant, des yeux malicieux qui contrastent avec une apparence un peu terrifiante dans son accoutrement et ses cheveux hirsutes). Elle me raconta son enfance dans le hameau, elle aurait dû être institutrice, mais la guerre ne le permit pas. J'accédai par cette rencontre à « la réception » des récits, au-delà de leur « observation». Les mots semblaient faibles pour dire. Les autres, «ceux qui ne connaissaient pas Henriette», ne semblaient effectivement pas en mesure de comprendre, ni de percevoir l'écart, qui existait dans toute parole sur Henriette, entre le signifiant et le signifié. Henriette faisait l'objet d'un processus de patrimonialisation à l'échelle locale. Une habitante du village me montra un jour son portrait sur le magazine Vents du Morvan en insistant: «Elle est pas belle notre Henriette!» Un journal ethnographique me permit alors une prise de distance par rapport à cet objet narratif.

Par la suite, les langues se délièrent en effet à mes oreilles dans le village et les récits sont arrivés par dizaines. La rencontre d'Henriette m'ouvrit la porte d'autres histoires un peu partout sur le territoire, à propos de femmes de plusieurs villages qui avaient les mêmes attributs qu'Henriette et dont les récits n'étaient dits que dans des circonstances similaires: La petite Louise, Jeanne, Charlotte, Ernestine, Alice et d'autres sont des figures narratives que j'ai étudiées et des personnes que j'ai pu rencontrer pour certaines. Les récits racontent la même chose: des femmes aux attributs masculins, au mode de vie marginal, très fortement attachées à leur lieu de vie, sorte d'extension d'elles-mêmes, des femmes subversives et en résistance face au progrès, seules (du fait d'une expulsion historique due à la guerre, à la mécanisation), «vieilles» (on ne raconte pas leur jeunesse), au centre des préoccupations et de l'organisation communautaire, au centre d'un système économique caractérisé par le troc (où l'équilibre entre don et contre-don est très spécifique), et vis-à-vis desquelles on parle de «saleté». Les mêmes configurations se retrouvent dans plusieurs dizaines d'identifications en Bourgogne, une vingtaine dans d'autres régions rurales (Cévennes, Limousin), des figures similaires en milieu urbain et récemment, des occurrences dans d'autre pays. Les récits sur ces femmes se situent entre la fascination et la peur, l'attraction 


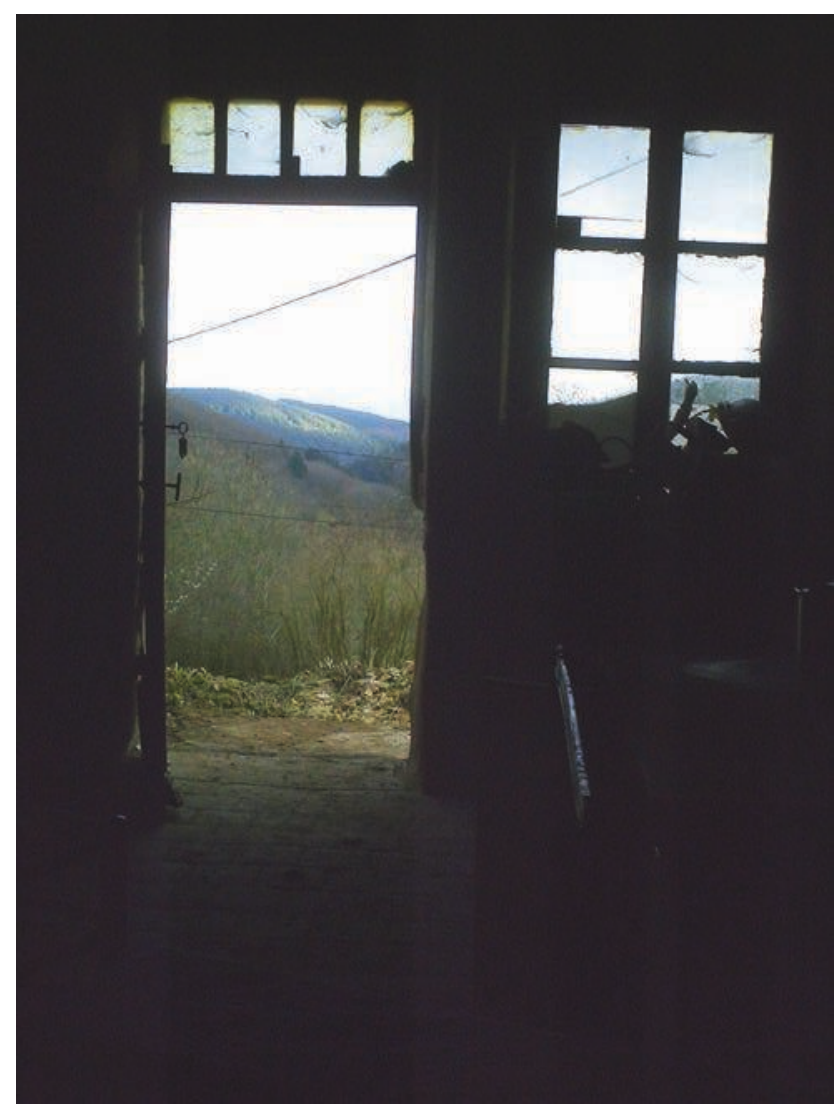

21 et 22. Dedans, Dehors. et la répulsion. Étudiés dans la diachronie, ces récits présentent une évolution majeure: pour les femmes nées avant 1920, on parle de vieilles femmes qui marchent et qui gardent l'espace communautaire: une cheville narrative qui va se retrouver dans nombre de contes merveilleux (collectés à la même époque) où le personnage de la vieille est gardienne, dans les récits légendaires où elle est un être topographique («la Beuffnie» dans le nord du Morvan, dans les Cévennes «la Vieille Morte» dans la vallée du Galeizon). Pour toutes celles qui sont nées après 1920: on raconte l'immonde de leur lieu de vie, notamment caractérisé par l'amas de restes, de "saletés», d'«immondices», et les excrétions ostentatoires (le corps qui coule: sang, urine, sueur). Il est dit notamment de ces vieilles femmes qu'«elles ne jettent rien», qu'«elles conservent tout ».

Un rapprochement quasi systématique se fait, dans la narration, entre le lieu de la vieille femme, sa vie, et les termes de « Moyen-Âge », d'«arriéré », «en retard», «étrange ». Il apparaît, de manière très précise, que parler de la vieille femme est une manière de parler du Morvan.

Très rapidement, Henriette mourut, l'hiver 2003 où le froid rigoureux et l'impossibilité de garder son feu allumé eurent sans doute raison d'elle, enfin le dit-on. Avec mon compagnon, nous cherchions un lieu de vie, ma quête en était à son début, il nous apparut évident que ce lieu était cette maison. Après l'avoir acquise, il nous fallut trier les cent soixante-dix mille litres de déchets qui jonchaient le sol, un peu partout à l'intérieur des bâtiments (nous le saurons en comptant les sacs-poubelles à la fin de l'ouvrage). Nous étions aidés dans ce labeur par plusieurs amis à qui nous avions donné le mot d'ordre: «On ne jette rien, on trie, on essaye de comprendre de quoi il s'agit, puis on évacue ce qui constitue réellement des déchets. »

Que désigne exactement cette saleté qu'on a peine à dire? Une série d'éléments très concrets relaient la référence à la saleté dans ce qui se raconte sur toutes ces vieilles femmes. Comme des leitmotiv, ils relient les récits entre eux: la fumée, la noirceur, la saleté qualifiant le mode par lequel elles habitent leur maison, l'encombrement, et au fil du temps, l'encombrement de détritus. On l'a vu, Henriette «met des saletés» qui coincent sa porte d'entrée, « elle n'a même pas le courage de les empiler ». D'autres témoins parlent d'une des pièces chez une autre vieille femme, Jeanne, habitante d'un autre village, qui était « très très encombrée, avec tout ce qu'elle trouvait, elle mettait contre le mur» des «cartons, des journaux». La description s'arrête alors que le témoin ne parvient pas à finir sa phrase: «C'était un petit peu...». De la même façon, d'autres 


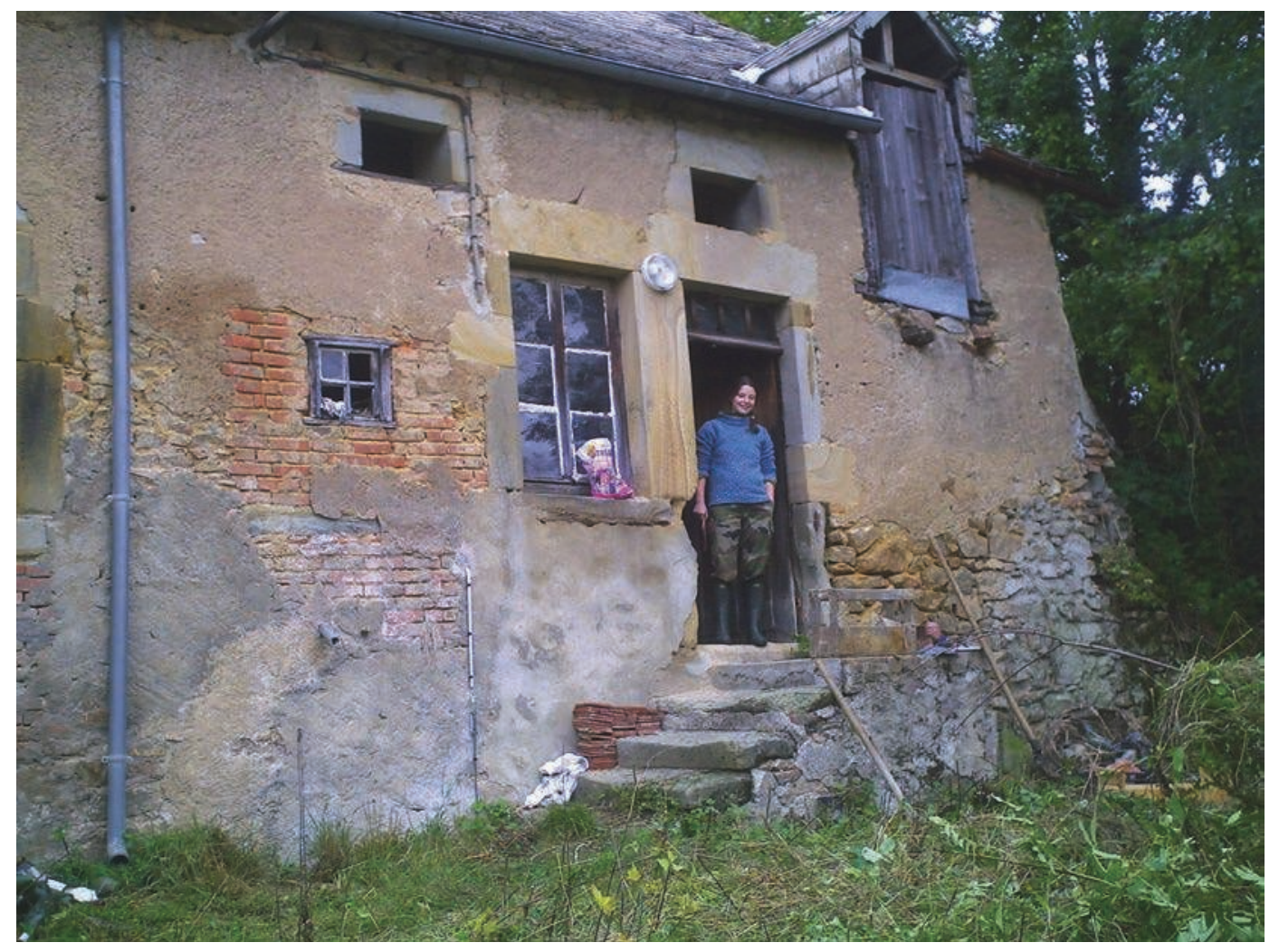

vieilles femmes, qui habitaient plus haut dans le massif, «réutilisaient et réutilisaient», elles suivaient strictement le principe de «ne pas jeter ».J'ai pu moi-même observer chez Alice, une autre de ces femmes, plusieurs amoncellements d'objets dans la cour et à l'intérieur, elle disait elle-même qu'elle consacrait une des pièces de sa maison à « empiler tout le fourbi » et qu'il y en a «jusqu'au plafond ». Un rapport des services sociaux établit qu'Ernestine, à Autun, « conserve tout. Aussi, le logement est un ramassis de vieux chiffons, bouteilles auxquels s'ajoutent les restes de repas non terminés». Cet encombrement bouleverse les repères. Julia Peker identifie très précisément le phénomène de saturation de l'expérience intime:

«Face au spectacle de l'immonde, l'aversion nous envahit avec une vivacité singulière: elle ruine le sentiment rassurant d'un factice inoffensif, interdit la mise à distance qui conditionne la possibilité même de la contemplation esthétique et la position de spectateur. » (Peker 2012).

Lors de l'archéologie des détritus d'Henriette, l'écriture du journal d'enquête fut l'une des clés qui me permit de sortir de «la fascination» exercée par le lieu et qui mit en exergue cette nécessité d'incorporer symboliquement la matière en récit. 

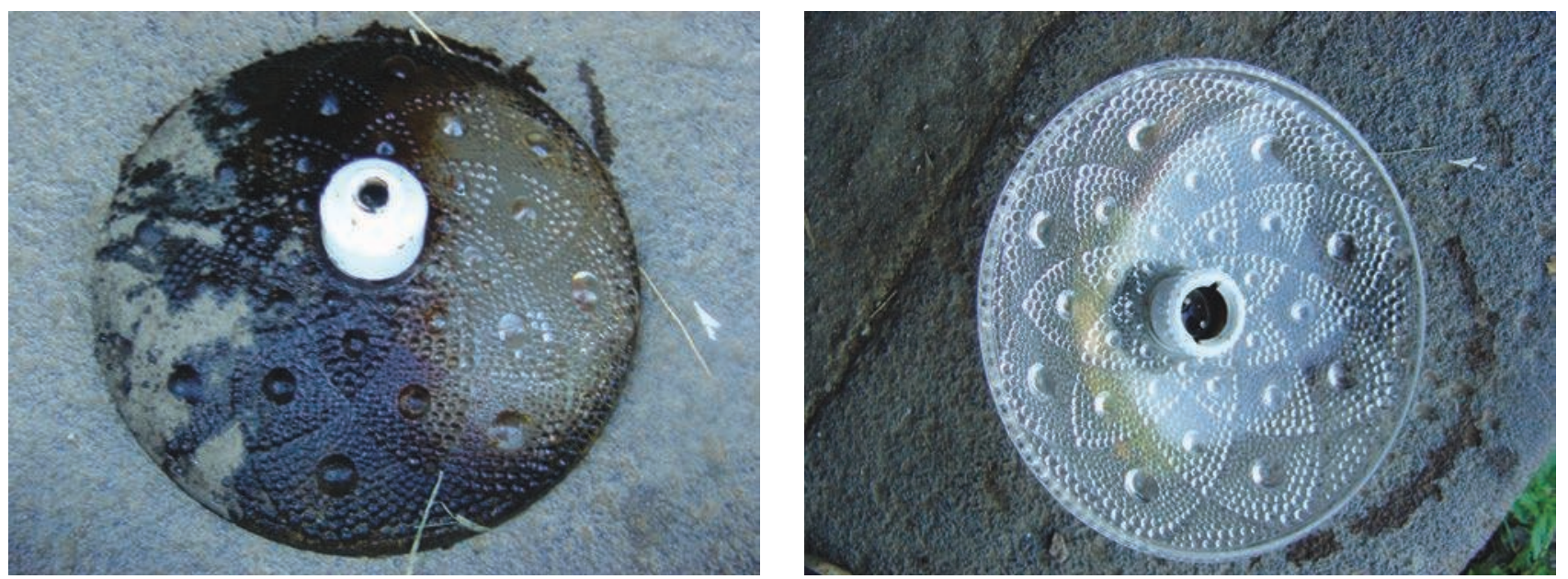

23 et 24 . Le propre et le sale.

Dans les témoignages, l'image de «l'antre de la sorcière », renvoyant à la stigmatisation de la sorcière historique (celle pourchassée par l'Inquisition), se lit en filigrane de ces descriptions. Cette image de «l'antre» envahit la tradition littéraire à partir du xvesiècle ${ }^{9}$. Les tableaux de Hans Baldung Grien, ceux de Brueghel l'Ancien puis plus tard de Jacob de Gheyn II, reprennent l'image de la vieille vautrée au milieu des immondices ${ }^{10}$. Dans l'économie du récit démonologique, «le bouillon» et «l'antre» tiennent une place spécifique. Ils sont le microcosme du renversement de valeurs et de logique opéré par la sorcière dans le monde chrétien, l'image concrète du chaos où s'assemble l'incompatible et où s'engendre l'immonde (inverse du monde). Ils sont surtout des motifs développés avec un épanchement sans fin de détails par le récit des autres: inquisiteurs, écrivains, poètes, peintres. Tout un imaginaire européen du lieu de vie de la vieille à la marge de la communauté se répand alors dans une symbolique généralisée (Arasse 2010). En cela, l'antre grouillant continue de témoigner, au fil des siècles, de la force que le groupe attribue à l'assemblement des éléments hétéroclites de la nature. Les récits sur les vieilles femmes de l'enquête dans le Morvan développent le même principe d'assemblement hétérogène des règnes et des éléments de la nature: animaux, nourriture, excréments, pourriture. S'y ajoutent le mélange des objets précieux et des déchets: pianos, richesses, cartons, plastiques et objets usagés. Les narrateurs insistent sur la force hors du commun de ces vieilles femmes, qui résistent aux charges, aux distances, aux travaux pénibles et à la douleur.

La tradition littéraire héritée de la période d'Inquisition et les récits issus de la transmission orale semblent se rejoindre (Ginzburg 1966) ${ }^{11}$. L'immondice et la saleté y désignent l'état naturel et permanent de la sorcière, comme une marque permettant de la reconnaître, au même titre que sa vieillesse, sa laideur et sa vie solitaire (Bechtel 2000) ${ }^{12}$. Ces croque-mitaines féminins «du seuil» sont très fréquents dans la tradition orale ${ }^{13}$. La même configuration se retrouve: une vieille femme solitaire habite dans les marges de la communauté (du bourg ou du village), et 
en matérialise les limites, elle se distingue par ses agissements inhabituels. Cette configuration manifeste, au fil du temps, une même nécessité narrative. La figure de la vieille semble traduire de tout temps une angoisse des limites (physiques, géographiques, culturelles, symboliques). Les confluences, dans la narration, entre la propreté du corps, du lieu de vie, et la pureté de l'âme sont signifiantes (Vigarello 1987, Caillois 1988). On voit comment cette forme verbale liée à la vieille femme est un moyen d'évacuation de l'angoisse générée par les alternatives aux normes socioculturelles. Aussi toutes ces vieilles femmes ne sont-elles pas les mêmes êtres narratifs mais leur fonction cathartique persiste.

Les photographies de l'intérieur de la maison d'Henriette, prises quelque temps après son décès, permettent de comprendre comment s'opère cette résurgence narrative: la pièce était froide, humide et noire de fumée. Plusieurs personnes affirmèrent revoir alors la pièce telle qu'elle était du vivant d'Henriette. Même si l'habitation de la vieille femme avait atteint un niveau extrême d'encombrement, elle n'était pas sans rappeler une autre tradition narrative. Depuis la fin du XIx siècle, les «réformateurs» du Morvan, tels que le docteur Monod, tentèrent d'éradiquer, en même temps que le retard historique et économique du massif, ce type de «maison ancienne» et primitive (Monod 1894). De manière générale au cours de l'enquête, dans une association d'idées assez répandue, le passé et l'insalubrité sont liés: les anciennes maisons sont insalubres, les maisons insalubres sont anciennes.

L'encombrement de détritus observé chez les vieilles femmes de cette étude semble pourtant un motif moderne. Le récit médical va à ce propos remotiver un récit antique autour de la désignation du syndrome de Diogène (Mac Millan \& Schaw 1966). Les personnes diagnostiquées, dont les femmes de cette étude, partagent la tendance au collectionnisme de «détritus», le récit médical utilise le terme "clochardisée», et le fait d'être plutôt des femmes, pour le reste, les médecins hésitent «entre pathologie psychiatrique et le choix de mode de vie marginal» (Macaigne 2007). La désignation du syndrome par le nom du philosophe cynique interroge: l'ascétisme de Diogène semble complètement à l'opposé de ce comportement accumulatif qui fonde pourtant le diagnostic du syndrome du même nom: il ne possède que son tonneau et un manteau déchiré. Le rapprochement du mythe et du syndrome passe par une projection symbolique. Ce qui rapproche, aux yeux des médecins, les comportements de Diogène et des patientes est clairement explicité: «le manque d'hygiène», «l'incurie», «la négligence», «l'insalubrité», «la saleté». Toutes désignations assez vagues qui renvoient à un lexique très marqué historiquement, et qui, d'un mode de contestation philosophique pendant l'Antiquité, deviennent un symptôme clinique et psychanalytique. Les pratiques assumées de souillure, jugées déviantes, sont le véritable signe qu'une limite est dépassée. Ce diagnostic, fondé sur l'observation d'une inadaptation sociale, s'articule donc nécessairement avec la perception que le médecin a de la norme. L'ensemble des études montre des degrés divers d'encombrement, d'accumulation et de décalage des pratiques, rassemblant en cela des réalités assez hétérogènes. La spéculation symbolique semble se mêler au diagnostic clinique. C'est bien le trouble subversif produit par ces femmes dans la société qui semble être à l'origine de la nomination du syndrome, sans que cela soit jamais explicité. Ces comportements compulsifs posent un véritable cas de conscience à la société de progrès. 
Cette souillure, expression du dépassement d'une limite instaurée par des règles sociales, religieuses ou culturelles (ce qui est saint, pur, sain, propre), est une marque qui apparaîtra peu à peu dans l'économie du récit sur la Vieille Femme. À mesure de l'avancée dans le siècle, les vieilles femmes sont racontées de plus en plus clochardisées et «sales». Cette tendance est révélatrice de temps forts des préoccupations hygiénistes au xxe siècle et notamment de leur résurgence récente dans l'espace public. Au début du xxe siècle, la Nourrice morvandelle incarnait cet idéal de corps sain, jeune et propre. Le réinvestissement du récit hygiéniste, comme soubassement d'un «pouvoir sur la vie», revient cycliquement dans le discours politico-social contemporain. Didier Fassin montre, entre autres, comment il fut largement médiatisé pour remplacer le débat politique sur les questions liées à l'immigration, à la paupérisation et à la marginalité en général:

«L'hygiénisme contemporain s'exprime peut-être plus [...] dans la lutte contre les fléaux sociaux qui ne sont pas de nature microbienne [...] la santé publique représenterait, en ce qu'elle semble héritière de la "police médicale", une forme aboutie de la normalisation des individus jusque dans leur intimité la plus quotidienne. » (Fassin 2001).

La référence au propre et au sale est le signe d'une implication forte, voire idéologique, du narrateur dans son récit.

Les diagnostics établis par le discours médical pour le syndrome de Diogène convergent vers l'interprétation d'une «maladie transitoire». Ian Hacking s'intéressa à cette notion à partir notamment d'une «épidémie de fugue » observée en France à la fin du xixe siècle (Hacking 2002). L'étude de ces «fous voyageurs» montre qu'ils n'ont existé en nombre important que durant les vingt-deux années qui suivirent le développement du chemin de fer. Ils marchaient sur le bord des routes, réalisant plusieurs dizaines de kilomètres par jour. Les «fous voyageurs » disparurent complètement ensuite. L'étude étaye l'hypothèse selon laquelle «il existe des maladies qui, non seulement n'ont pas de marqueurs biologiques clairs, mais en plus n'apparaissent qu'à des époques et en des lieux bien particuliers» (Hacking \& Ruphy 2004). D’une manière globale, la modernité a engendré des bouleversements et des traumatismes tels que l'attention médicale et collective se focalisa sur certains comportements nouveaux qui remettaient en question les bienfaits du progrès. On peut lire, dans ces deux troubles transitoires, la suite de fragmentations opérées par la modernité: fragmentation du lieu, puis du corps. Louise et Jeanne (nées entre 1880 et 1920) sont en partie évoquées avec les attributs narratifs atténués des «fous voyageurs » et ceux débutants des Diogène. Henriette, les sœurs de Saint-Léger, Ernestine et Alice (nées après 1920) sont racontées, et se racontent, avec les symptômes avérés de cette seconde pathologie transitoire.

J'ai tenté de confronter les étapes narratives consignées dans mon journal avec les récits collectés auprès de l'ensemble des témoins: un processus récurrent est apparu, où l'immonde, le contact avec les restes et leur odeur, l'expérience tangible des déchets, permettent d'accéder au système de représentation paradoxal de la vieille femme, et déclenchent une refiguration de l'expérience intime. Le système de représentation s'inverse. L'opposition normative du Propre et du Sale se dissout pour en dévoiler une plus spatiale: le Vide et le Plein, puis une qui tend davantage à l'universel, celle qui distingue le Même et l'Autre. Précisément, le contact avec la 


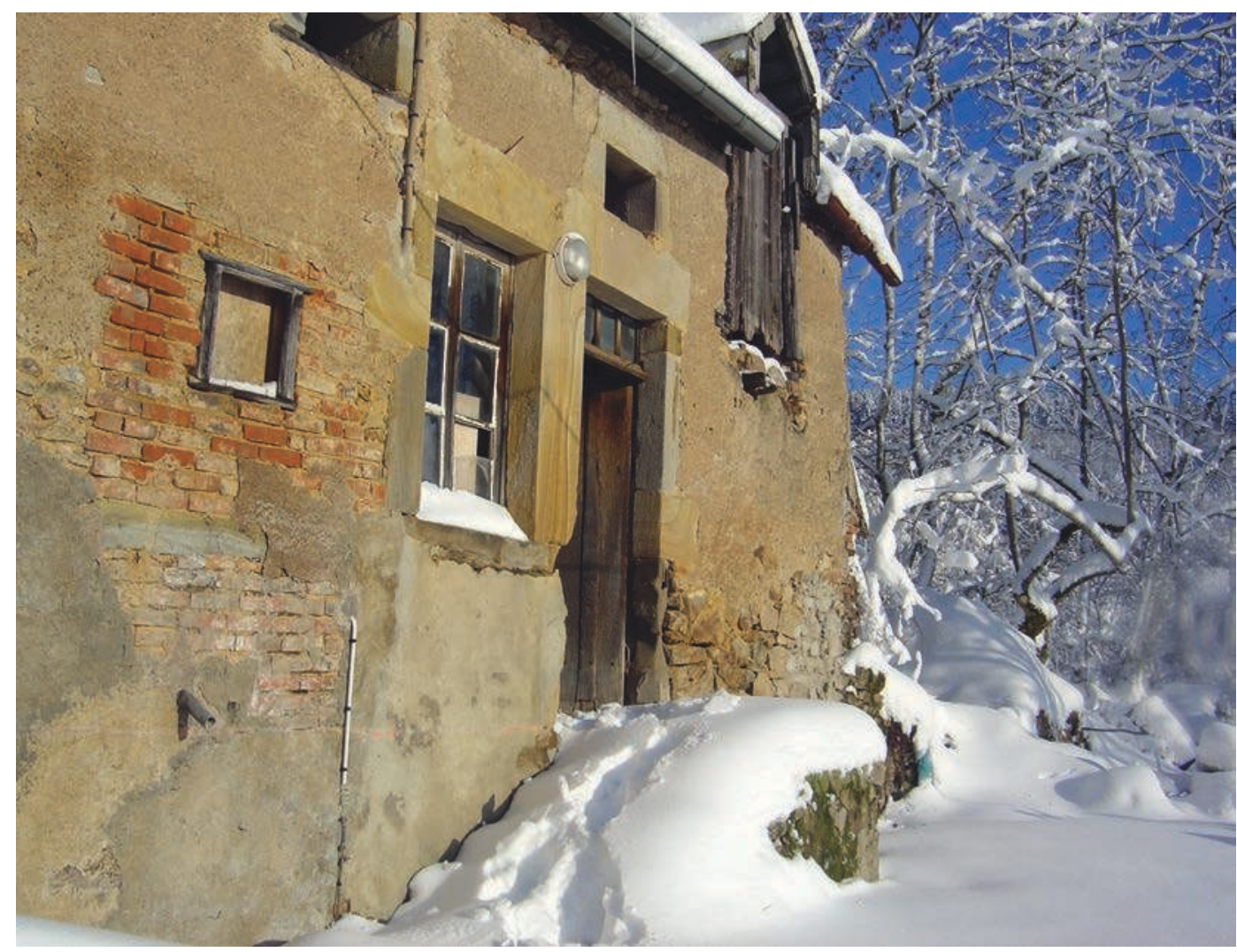

25. Rencontre et récits.

saturation de la matière de ce lieu confine la parole à l'indicible, car il provoque un phénomène de sidération, cette saturation va constituer un réservoir symbolique dans le champ du concret: cela va ouvrir les possibilités signifiantes (la terre recouvre littéralement une chaise jusqu'à faire croire que l'extérieur est à l'intérieur de la maison, les chats noirs signent le malheur devant celle «qui n'a pas eu de chance», la vieille femme inquiétante ne répond qu'au cri de la chouette, un tableau actualise la présence réelle de l'être qui l'a possédé $\left.{ }^{14}\right)$. Cette recherche fait émerger un processus collectif de singularisation autour d'une figure narrative, celle de la vieille femme salie, qui s'inscrit dans une historicité, et qui s'accroche à des personnes réelles dont le mode de vie est en résistance avec le récit de progrès. Cette résistance a trait à leur manie de garder, d'accumuler, de ne pas jeter. On les désigne comme sale, mais cette saleté renvoie à autre chose.

Dès après la Révolution, avec une accélération entre 1850 et 1950 et une acmé après la seconde guerre mondiale, l'hygiène privée et publique a conquis tous les domaines de pratique, " "l'hygiénisation de la vie quotidienne" s'est opérée dans un mouvement de spirale ascendante, déplaçant à chaque fois les paliers de salubrité et les seuils de tolérance des habitants» (Kalff 2001). La subversion de cette norme prend une valeur générale car elle touche tous les champs 
26. Saletés : résurgence narrative.

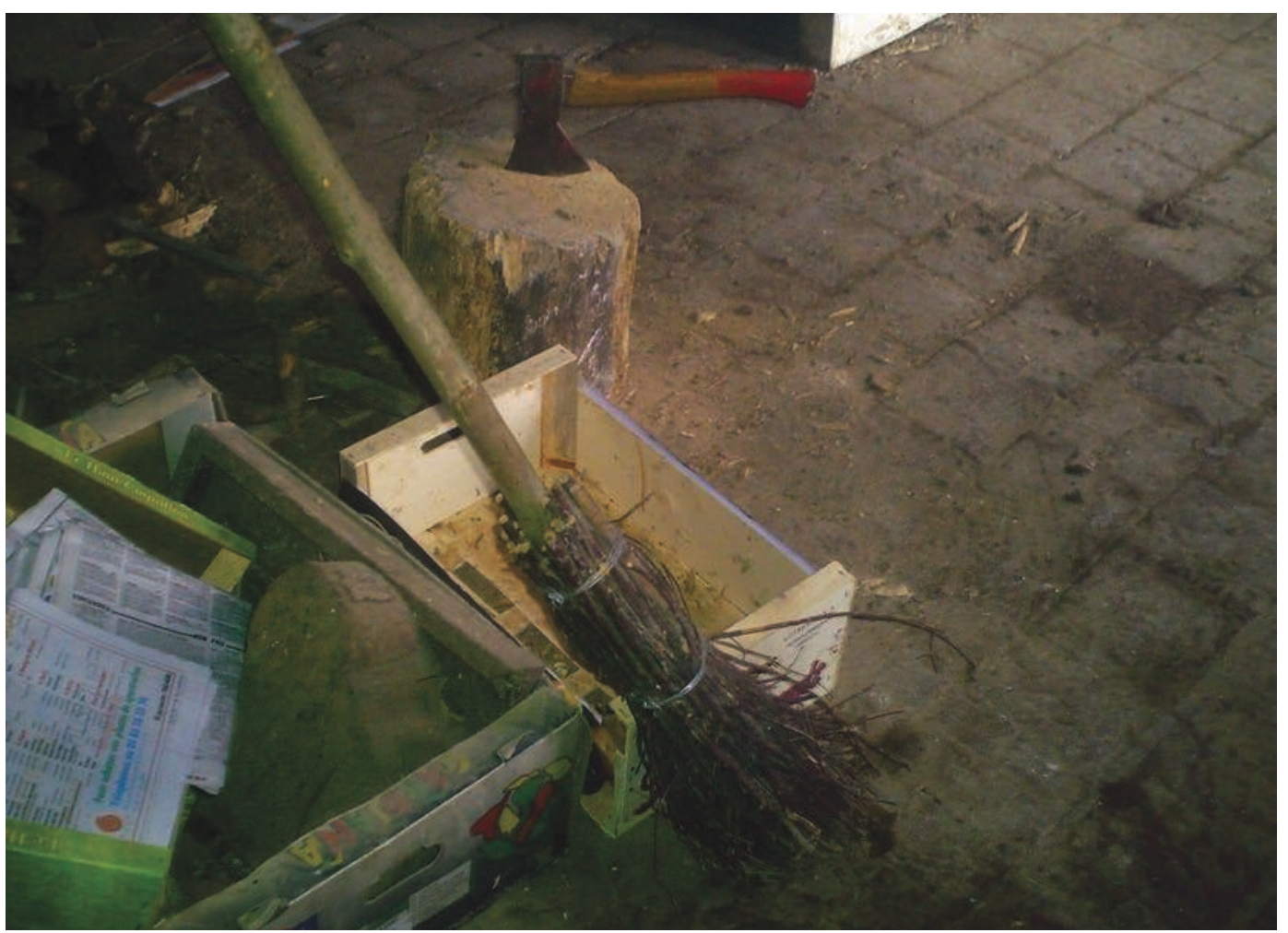

de pratiques que l'hygiénisme a bouleversés: les pratiques intimes liées au corps mais aussi l'habitat, la médecine, l'économie. La souillure apparaît dans la narration comme le mode privilégié de transgression de la norme, un moyen de contestation et l'expression collective et concrète d'une souffrance engendrée par l'Histoire. On peut se demander depuis quelle période les vieilles des limites, les croque-mitaines de l'entrée des villages ont été désignés par leur «saleté». Un marqueur de la réactivation de ce phénomène à l'échelle nationale est la floraison, dans les années 1980-1985 de multiples articles de presse relatant la «découverte» des déchets entassés chez des vieilles femmes, en voici un exemple particulièrement frappant dans les matériaux symboliques convoqués par le journaliste:

«Blanche, reine de son immeuble-poubelle. Une odeur de pourriture et de malaise. Après la découverte de plusieurs tonnes de détritus accumulées par une vieille dame de 82 ans... Quand on l'interroge: "Cela fait quarante-sept ans que je fais le ménage et que je nettoie tout, voilà comment on me remercie!"», Libération, 20 février 1985.

On pourrait étudier ce phénomène à l'échelle des rapports sociaux entre populations dominées et dominantes, à l'échelle mondiale entre pays du Nord et du Sud. 
La communauté villageoise rencontrée au cours de cette recherche récupère un comportement d'accumulation de restes, celui d'Henriette, d'Alice et des autres vieilles femmes que l'on raconte entre soi, pour exprimer ses propres pertes: perte des temps anciens et d'un système de représentation bouleversé par la société de progrès. Ainsi le récit individuel de la vieille femme devient instrument du récit collectif du territoire de parole, forgeant une figure de résistance contre le récit dominant. La Vieille Femme assemble des occurrences multiples, elle répond à la nécessité pour certains groupes de résister à la décomposition et à la partition de leur horizon intime, produites par l'Histoire et régies, depuis deux siècles, par la binarité dominante du propre et du sale. L'ethnographie de la Vieille Femme Sale a permis de faire apparaître un écart entre les temporalités vécues par les uns et les autres à travers un bouquet de récits de vie. En questionnant ces temporalités et en les éclairant par un regard kaléidoscopique, l'analyse a fait émerger le visage de la Vieille Femme Salie. La Vieille Femme fut Salie, le corps marqué par la souffrance de la disjonction de son récit intime avec les grands récits nationaux, reflet gémellaire de la mutilation historique du récit morvandiau. Une saleté produite par les préceptes hygiénistes qui instaurèrent durablement une confusion entre «la trace d'un passé » et «la souillure»: la persistance du passé dans le temps présent se matérialisa négativement en restes; le bas du corps renvoya à une part maudite de l'expérience devenue l'immonde de la modernité. Le récit de la Vieille Femme Salie permet de raconter l'Histoire telle que le point de vue endogène la souhaiterait. Ainsi s'aménage au quotidien, dans le travail de l'identité narrative, l'Autre du récit de progrès, la réconciliation entre les deux figures contradictoires du récit morvandiau: la Vieille Femme Salie et la Nourrice, figure accomplie du Progrès, caractérisée par sa jeunesse, sa propreté irréprochable et son ascension sociale. On pourrait se pencher sur l'analyse narrative des photographies, celles que j'ai prises et que je vous ai présentées plus haut, l'imaginaire dont elles procèdent. Dans la carte postale représentant la vieille femme du Morvan, prise aux environs de 1900, on voit comment les attributs et le cadre choisis pour photographier la vieille femme font sens: grand vêtement sombre et saletés, au contraire de la nourrice, photographiée à la même période.

Par les effets littéraires utilisés dans cet article, j'ai souhaité permettre au lecteur de mesurer l'épaisseur du continuum narratif (récit intime, récit social, récit historique, grands récits, discours scientifique) par lequel se travaille au quotidien, dans l'implicite et l'explicite, dans un métissage entre matérialité et récit de la matière, cette refiguration du monde à partir de ses restes. 


\section{Notes}

1. John Berger et Jean Mohr questionnent la dialectique qui existe entre le langage des apparences et l'expérience vécue, ils ont expérimenté en ce sens le récit photographique (Berger, J. \&J. Mohr 1981).

2. J'utilise «refiguration» comme troisième temps de la dynamique narrative, préfiguration/configuration / refiguration, où s'établit une dialectique entre le récit et le vécu, ainsi que Paul Ricœur l'a magistralement décrit dans les trois volumes de son ouvrage Temps et récit. Le récit induit la perception du vécu, engendrant un rapprochement avec un récit déjà entendu qui, une fois raconté, induira à son tour la perception que les auditeurs auront de leur propre vécu. Jalonné par ces interactions narratives, le temps de la vie évolue dans un mouvement cyclique mais en devenir, comme un ressort qui impulserait sans cesse la nécessité pour l'homme de raconter. Récit et temporalité de l'expérience sont étroitement liés dans le discours comme si le premier produisait le second, selon une dialectique qui montre que le récit est «le gardien du temps, dans la mesure où il ne serait de temps pensé que raconté» (Ricour 1985: 435). Cette dynamique à trois temps, s'observe à tout niveau de production narratif: qu'il soit celui du terrain ou celui du chercheur.

3. Cette tentative vient en résonance avec celle de Florence Weber dans son Manuel de l'ethnographe. Elle y explore notamment les modalités de perception et de recomposition du réel dans le journal de terrain, journal de recherche, journal intime de l'ethnologue (Weber 2009).

4. A. Millien Fonds Ms 46-55. Nevers: Archives départementales de la Nièvre 1922.

5. Cf. entre autres les travaux de J.-B. Renard Rumeurs et légendes urbaines. Paris: PUF 1999.

6. D'une superficie de $2900 \mathrm{~km}^{2}$, il représente 120 communes, 52000 habitants.
7. P. Vidal De La Blache Tableau géographique de la France, Paris: Hachette, 1903: 112.

8. G. Roupnel, La Bourgogne. Paris: Horizons de France, 1936: 11 et ss.

9. En examinant les correspondances narratives, il est intéressant de comparer les évocations de ces antres et celles qui tentent de traduire la maison de ces vieilles femmes contemporaines. Cf. la «tesniere» (tanière) de la Sibylle de Pansouste, «la case chaumine mal bastie, mal meublée, toute enfumée » que Panurge et Epistémon viennent visiter (F. Rabelais, Le Tiers Livre, Paris: LGF, 1995 [1546] : 169-171).

Elle est évoquée dans des traits préfigurant ceux des sorcières de Macbeth.

10. Hand Baldung Grien, Scène de sorcellerie, [gravure sur bois], 1510. Cf. aussi Pieter Bruechel l'Ancien, Saint Jacques le Majeur chez les magiciens Hermogène, [gravure], 1565; Jacob de Gheyn II, Les Sorcières, Ashmoleon Museum, Oxford, 1600.

11. Les travaux de Carlo Ginzburg ont montré comment les imaginaires démonologiques et traditionnels ont pu se contaminer, s'influencer au détriment des croyances traditionnelles.

12. Guy Bechtel dresse à partir de la fin du xve siècle le portrait-robot de la sorcière dont il observe la persistance jusqu'au Xvil ${ }^{e}$ siècle, même s'il note des évolutions, notamment dans l'âge des inculpées.

13. Cf. Yvonne Verdier sur la maison de la Mère Lusine: «La mère Lusine, c'était une femme sale, ça oui, on disait: "sa maison c'est une vraie usine" [ ]. Elle était à l'entrée des pays [ ] il fallait avoir un mouchoir pour lui torcher le cul» (Verdier 1973). Également Charles Joisten (Joisten, Abry \& Joisten 2005-2009).

14. Cf. l'étude de «l'incarnation» et de «l'actualisation» des ancêtres dans l'analyse du Sacré de transgression de Roger Caillois (Caillois 1988 [1950] : 128-168).

\section{I'auteure}

Caroline Darroux est ethnologue. Elle travaille sur les aspects performatifs des récits oraux, sur la production de récits collectifs selon une approche critique des phénomènes d'émancipation sociale. Elle s'intéresse au renversement des problématiques d'exclusion et d'expression en situation dominée (en collaboration avec le Centre Georges Chevrier, université de Bourgogne et le labex Item, université de Grenoble-Alpes). Chercheure impliquée dans la société civile, elle est coordinatrice scientifique de la Maison du Patrimoine Oral de Bourgogne et accompagne depuis 2014 des démarches de participation citoyenne (Les Ateliers co-citoyens). Ses réflexions la mènent régulièrement vers des démarches qui croisent anthropologie et création artistique en dehors des arènes scientifiques. 


\section{Iconographie}

Image d'ouverture. Huile sur carton, 12 x $20 \mathrm{~cm}$. Branche de fleurs d'églantines. Une déchirure en haut à gauche du dessin sectionne quelques pétales et laisse apparaître une certaine épaisseur du support. Au dos, une écriture manuscrite se devine: «Lettres de [1 mot illisible] reçues par Mademoiselle Margueritte Lépagnol». J’ai retrouvé cet objet en 2005 au milieu d'une épaisseur de déchets d'environ dix à quinze centimètres qui jonchaient le sol de la maison d'habitation d'Henriette située dans un hameau isolé du Morvan, en Bourgogne. Je ne suis pas parvenue à identifier cette Margueritte. (C) Collection privée (C. Darroux).

1, 2, 3. C Collection privée (M. Desmorieux).

4. C) Collection privée (R. Guillaumeau).

5. (C) C. Lagriffe.

\section{Références}

Arasse, D. 2010 Le Portrait du diable. Paris: Arkhê.

Bechtel, G. 2000 Les Quatre femmes de Dieu. La putain, la sorcière, la sainte et Bécassine. Paris: Plon.

Berger, J. \& J. Mohr 1981 Une Autre façon de raconter. Paris: Maspéro.

Caillois, R. 1988 [1950] L'Homme et le sacré. Paris: Gallimard.

Darroux, C. 2011 La Vieille femme salie. Récit d’une résistance à la modernité (Morvan XXé-xxI siècles). Thèse de Doctorat. Aix-en-Provence: Université de Provence.

Fassin, D. 2001 «Les scènes locales de l'hygiénisme contemporain. La lutte contre le saturnisme infantile: un bio-politique à la française» in P. Bourdelais dir. Les Hygiénistes: enjeux, modèles et pratiques. Paris: Belin: 447-465.

Ginzburg, C. 1966 Les Batailles Nocturnes. Sorcellerie et rituels agraires en Frioul, XVIe-XVII siècles. Lagrasse: Verdier.

Glissant, E. 1996 Introduction à une poétique du divers. Paris: Gallimard.

Hacking, I. 2002 Les Fous voyageurs. Paris: Les Empêcheurs de penser en rond.

Hacking, I. \& S. Ruphy 2004 «La fabrication des malades» in La Recherche, hors série, 16/2004: 46-48.

Joisten, Ch., Abry, N. \& A.Joisten 2005-2009 Êtres fantastiques du Dauphiné, 4 tomes. N. Abry \& A. Joisten (ed.). Grenoble: Musée dauphinois.

Jolles, A. 1930 Formes simples. Paris: Seuil.

Kalff, E. 2001 «Les plaintes pour l'insalubrité du logement à Paris (1850-1955), miroir de l'hygiénisation de la vie

\section{Pour citer cet article}

Darroux, C. 2016 «Refigurer le monde. La vieille femme salie: ses restes, ses narrations, sa résistance (Morvan XxxxI ${ }^{e}$ siècles)», TechniquesECulture 65-66 «Réparer le monde. Excès, reste et innovation », p. 470-493.
6. (C) Vents du Morvan.

11. (C) Collection University of Oxford, Ashmoleon Museum. 7 à 10 et 12 à 26. (c) C. Darroux.

quotidienne» in P. Bourdelais dir. Les Hygiénistes: enjeux, modèles et pratiques. Paris: Belin.

Mac Millan, D. \& P. Schaw 1966 «Senile Breakdown in Standards of Persona Land Environnemental Cleanliness », British Medical Journal 271 : 1032-1037.

Macaigne, G. et al. 2007 «Le syndrome de Diogène associé à l'éthylisme chronique: présentation de deux cas », La Revue de Gériatrie (32) 2: 133-136.

Monod, Dr 1894 «Les maisons types dans la région de Montsauche (Morvan)» in Enquête sur les conditions de l'habitat en France. Paris: Leroux, 373-378.

Peker, J. 2012 Cet obscur objet du dégoût. Paris: Le bord de l'eau.

Pelen, J.-N. 2008 «Entre intime, histoire et Grands Récits: l'assemblement narratif du Sujet » in M. Crivello \& J.-N . Pelen Individu, récit, histoire. Aix-en-Provence: PUP.

— 2004 «Ethnographie du récit» in B. Mesini, J.-N. Pelen, \& J. Guilhaumou Résistances à l'exclusion. Récits de soi et du monde. Aix-en-Provence: PUP.

Renard, J.-B. 1999 Rumeurs et légendes urbaines. Paris: PUF. Ricœur, P. 1990 Soi-même comme un autre. Paris: Seuil.

— 1983-1985 Temps et récit. 3 tomes. Paris: Seuil.

Segalen, V. 1978 Essai sur l'exotisme. Une esthétique du divers. Saint-Clément: Fata Morgana.

Verdier, Y. 1973 Façons de dire, façons de faire. La laveuse, la couturière, la cuisinière. Paris: Gallimard.

Vigarello, G. 1987 Le Propre et le sale. L'hygiène du corps depuis le Moyen Âge. Paris: Seuil.

Weber, F. 2009 Manuel de l'ethnographe. Paris: PUF (Quadrige) 